Article

\title{
Studies on the Potential of Nonmodified and Metal Oxide-Modified Coal Fly Ash Zeolites For Adsorption of Heavy Metals and Catalytic Degradation of Organics for Waste Water Recovery
}

\author{
Silviya Boycheva ${ }^{1, *(\mathbb{D})}$, Denitza Zgureva ${ }^{2, *}{ }^{\mathbb{D}}$, Simona Miteva $^{1}$, Ivan Marinov ${ }^{1}$, \\ Dominika Marcin Behunová ${ }^{3}$, Ivalina Trendafilova ${ }^{4}$, Margarita Popova ${ }^{4}$ and \\ Miroslava Václaviková 3 (D) \\ 1 Department of Thermal and Nuclear Power Engineering, Technical University of Sofia, 8 Kl. Ohridsky Blvd., \\ 1000 Sofia, Bulgaria; smiteva@tu-sofia.bg (S.M.); ivankmarinov@tu-sofia.bg (I.M.) \\ 2 College of Energy and Electronics, Technical University of Sofia, 8 Kl. Ohridsky Blvd., 1000 Sofia, Bulgaria \\ 3 Institute of Geotechnics, Slovak Academy of Sciences, Watsonova 45, SK-043 53 Kosice, Slovak Republic; \\ behunova@saske.sk (D.M.B.); vaclavik@saske.sk (M.V.) \\ 4 Institute of Organic Chemistry with Centre of Phytochemistry, Bulgarian Academy of Sciences, 1113 Sofia, \\ Bulgaria; ivtrendafilova@gmail.com (I.T.); mpopova@orgchm.bas.bg (M.P.) \\ * Correspondence: sboycheva@tu-sofia.bg (S.B.); dzgureva@tu-sofia.bg (D.Z.)
}

Received: 9 May 2020; Accepted: 29 June 2020; Published: 3 July 2020

check for updates

\begin{abstract}
A nanocrystalline zeolite of Na-X type (CFAZ) was synthesized by ultrasonic-assisted double stage fusion-hydrothermal alkaline conversion of lignite coal fly ash. Modified CFAZ with magnetic nanoparticles (MNP-CFAZ) was obtained by adding presynthesized magnetic nanoparticles between the synthesis stages. CFAZs loaded by particles of copper (Cu-CFAZ) and cobalt (Co-CFAZ) oxides were prepared by postsynthesis modification of the parent CFAZ, applying a wet impregnation technique. The parent and modified CFAZs were examined for their phase composition by X-ray diffraction, morphology by scanning electron microscopy, and surface characteristics by $\mathrm{N}_{2}$ physisorption. Comparative studies have been carried out on the adsorption capacity of the starting CFAZ and its derivatives with respect to $\mathrm{Cd}^{2+}$ - and $\mathrm{Pb}^{2+}$-ions from aqueous solutions. Adsorption isotherms of $\mathrm{Cd}^{2+}$-ions on the studied samples were plotted and described by the adsorption equations of Langmuir, Freundlich, Langmuir-Freundlich, and Temkin. The best correlation between the experimental and model isotherms for the parent and modified CFAZ was found with the Langmuir linear model, assuming a monolayer adsorption mechanism. Parent and modified CFAZs were also studied as catalysts for heterogeneous thermal Fenton oxidation of methylene blue. At $90^{\circ} \mathrm{C}$, the higher catalytic activity exhibits the nonmodified sample, but with the decrease in temperature to $60^{\circ} \mathrm{C}$, the modified samples are more effective catalysts.
\end{abstract}

Keywords: coal fly ash zeolites; heavy metals; wastewater remediation; Fenton oxidation

\section{Introduction}

Coal fly ash (CFA) is a solid byproduct of coal combustion in thermal power plants (TPPs). Due to the widespread use of coal for global energy production, CFA is being generated in huge quantities. In recent years, opportunities for smart utilization of this solid waste have been intensively explored with the aim to reduce its landfill and to utilize its resource as a source of valuable raw materials [1-3]. As the coal ash in its macrocomposition is predominantly aluminosilicate material, technological approaches to its conversion into zeolites are intensively studied [4]. The synthesis of coal fly ash zeolites (CFAZs) 
is based on the alkaline dissolution of the silica and alumina components of its composition, formation of a hydrogel, and its heterogeneous crystallization in a particular zeolite phase [5]. The alkaline conversion of coal ash is most efficiently accomplished by one-stage hydrothermal or two-stage hydrothermal-fusion syntheses $[4,6]$. The single hydrothermal treatment is usually performed at mild temperatures (below $100^{\circ} \mathrm{C}$ ), while in the two-step synthesis prealkaline fusion of the reaction mixtures is generally performed at $550{ }^{\circ} \mathrm{C}$, followed by hydrothermal activation in the thermal range of $35-90{ }^{\circ} \mathrm{C}[7,8]$. The high-thermal treatment facilitates the alkaline dissolution of the persistent silicate and alumosilicate crystalline phases usually found in the CFA composition, such as quartz $\left(\alpha-\mathrm{SiO}_{2}\right)$, mullite $\left(3 \mathrm{Al}_{2} \mathrm{O}_{3} 2 \mathrm{SiO}_{2}\right)$, and anorthite $\left(\mathrm{CaAl}_{2} \mathrm{Si}_{2} \mathrm{O}_{8}\right)$, whereby they are also converted into zeolites, and the obtained products are highly zeolitized [9]. The CFAZs are characterized by a sufficiently developed specific surface suitable for adsorption and catalytic applications [10]. Moreover, unlike their pure synthetic analogs, CFAZs possess a mixed micromesoporous structure that allows them to host and trap species of different diameters in their structural framework [10]. The outer surface of the zeolite powders can also be greatly enlarged by applying ultrasonic homogenization of the reaction slurries of coal ash and alkaline solutions preceding their synthesis [11]. In this way, the highly developed interphase boundaries will favor the efficiency of these materials in water and gas cleaning applications [12]. The CFA has been found to contain significant amounts of iron oxide phases in the form of hematite $\left(\alpha-\mathrm{Fe}_{2} \mathrm{O}_{3}\right)$, magnetite $\left(\gamma-\mathrm{Fe}_{3} \mathrm{O}_{4}\right)$, and maghemite $\left(\gamma-\mathrm{Fe}_{2} \mathrm{O}_{3}\right)$ [13]. In the alkaline conversion of CFA by a single-step hydrothermal synthesis, the iron oxide phases of the feedstock are transferred to the zeolite product without undergoing phase changes. Since $\gamma-\mathrm{Fe}_{3} \mathrm{O}_{4}$ and $\gamma-\mathrm{Fe}_{2} \mathrm{O}_{3}$ are ferrimagnetic, they also give magnetic properties to the hydrothermally synthesized CFAZs [14]. However, in the two-step synthesis, during the high-thermal stage, the ferrimagnetic phases of the ash composition are oxidized to paramagnetic hematite, and the products have no magnetic properties [15]. Magnetically active zeolites are valuable in water purification since, at the end of the process, they are easily removed from the aqueous medium by an applied external magnetic field [16]. Zeolites have long been used in the purification of contaminated water from organic pollutants, heavy metals, and some inorganic anions due to their strong adsorption capacity and ion exchange properties obeyed by their specific highly porous structure with mobile compensating cations $[17,18]$. CFAZs of faujasite (FAU, $\mathrm{Na}-\mathrm{X}$ ), linde (LTA, A), and gismondine (GIS, Na-P1) types are among the most studied adsorbents and ion exchangers for heavy metal uptake from contaminated waters $[19,20]$. The significant potential of CFAZs to eliminate effectively, separately or simultaneously, a variety of heavy metal ions such as $\mathrm{Ni}^{2+}, \mathrm{Mn}^{2+}, \mathrm{Cd}^{2+}, \mathrm{Co}^{2+}, \mathrm{Cs}^{2+}, \mathrm{Hg}^{2+}, \mathrm{Cu}^{2+}, \mathrm{Pb}^{2+}, \mathrm{Zn}^{2+}$, and $\mathrm{Cr}^{2+}$ from polluted water has been observed [21-23]. CFAZs are also able to adsorb dyes and a variety of organic contaminants from water, reaching significant dye removal efficiency $[24,25]$. Iron-embedded zeolites have been studied as catalysts for a heterogeneous Fenton oxidation process applied for degradation of organic contaminants from water [26]. Fenton reaction is based on the production of oxidative hydroxyl and hydroperoxyl radicals by chain reactions of photo or thermal degradation of $\mathrm{H}_{2} \mathrm{O}_{2}$ catalyzed by $\mathrm{Fe}^{2+}$ - and $\mathrm{Fe}^{3+}$-ions. Some of the most effective Fenton catalysts are natural or synthetic zeolites loaded with ferrous salts or magnetite particles $[27,28]$. Fenton-like catalysts based on zeolites modified by other metal oxides have been recently studied [29]. The CFAZs have attracted the attention of researchers as catalysts for Fenton oxidation processes because they contain iron oxides in the form of magnetite, maghemite, and hematite, which are transferred from the raw coal ash [30,31]. In addition, they can be modified with different metal oxides to improve their catalytic properties [32,33]. Some comparative studies have revealed that the removal capacities of CFAZs are rather lower as compared to the widely used in practice adsorbents; however, their substantially lower cost and the complex environmental benefits of coal ash utilization make them promising adsorbents for wastewater treatment with great potential to remove a range of pollutants [34]. However, by the synthesis of nanoscale CFAZs and/or by their in-situ or postsynthesis modification, their adsorption capacity can be greatly enhanced to exceed that of pure synthetic zeolites [35,36]. Thanks to their low cost and comprehensive retention capability, CFAZs have been considered as effective sorbents in barriers against infiltration and for immobilization 
of pollutants in the soil [23]. In addition, recent studies on CFAZs reveal that although they carry heavy metals transferred from the raw ash, the leaching of harmful ions into the contact media is not observed over a wide $\mathrm{pH}$ range, making them safe for water decontamination [37].

This study seeks to clarify the applicability of CFAZs of Na-X type obtained by ultrasonic-assisted double stage fusion-hydrothermal alkaline conversion of lignite coal fly ash and their metal oxide-modified derivatives for remediation of polluted water. The sonicated CFAZs of Na-X type are characterized by highly developed total and external specific surface areas due to their nanocrystalline morphology and mixed micromesoporous structures. The combination of the two-step synthesis with the prealkaline melting of the reaction mixtures and the ultrasonic treatment of the suspensions ensures a fine distribution of the iron oxide particles in the zeolite structural framework [13]. It is expected that this unique combination of textural features of the parent CFAZs, as well as their further modification with nanoparticles of magnetic iron, copper, and cobalt oxides, will contribute to the high adsorption capacity and catalytic activity of these materials in the remediation of water contaminated with heavy metals and organic matter.

\section{Materials and Methods}

\subsection{Synthesis of Non-Modified and Metal Oxide-Modified CFAZs}

The CFA from lignite coal containing $70 \mathrm{wt} \% \mathrm{SiO}_{2}+\mathrm{Al}_{2} \mathrm{O}_{3}$ and $15 \mathrm{wt} \% \mathrm{Fe}_{2} \mathrm{O}_{3}$ was used as a raw material for the synthesis of zeolites. The nonmodified CFAZ samples were prepared by a double-stage fusion-hydrothermal synthesis. Solid mixtures of CFA and $\mathrm{NaOH}$ (pure for analysis, Valerus, Sofia, Bulgaria) in a ratio of $1: 2$ were fused in Ni-crucibles at $550{ }^{\circ} \mathrm{C}$. The resultant products were cooled down to ambient temperature, diluted in $100 \mathrm{~mL}$ distilled water and sonicated for $15 \mathrm{~min}$. As a second stage, the reactant liquors were hydrothermally activated at $90^{\circ} \mathrm{C}$ for $4 \mathrm{~h}$ in closed containers. After the syntheses, the precipitates were filtered, washed repeatedly with distilled water, and dried at $105^{\circ} \mathrm{C}$ for $1 \mathrm{~h}$. CFAZs were loaded with magnetic nanoparticles (MNPs) by adding $4 \mathrm{wt} \% \mathrm{MNPs}$ to the reaction mixtures between the fusion and hydrothermal stages (in situ modification). MNPs were uniformly spread into the reaction slurries via sonication. MNPs were preliminary prepared by dissolving $0.01 \mathrm{~mol} \mathrm{FeCl}_{2} \cdot 4 \mathrm{H}_{2} \mathrm{O}$ (pure for analysis, Chempur, Piekary Ślaskie, Poland) and $0.02 \mathrm{~mol} \mathrm{FeCl}_{3} \cdot 6 \mathrm{H}_{2} \mathrm{O}$ (pure for analysis, Chempur, Piekary Ślaskie, Poland) in $100 \mathrm{~mL}$ deionized water. The reaction solution was kept at $25^{\circ} \mathrm{C}$ in a water bath and stirred under $\mathrm{N}_{2}$ flow at $500 \mathrm{rpm}$. A solution of $8 \mathrm{~mol} \mathrm{NaOH}$ (pure for analysis, Valerus, Sofia, Bulgaria) was added continuously under stirring for $3 \mathrm{~h}$ until final $\mathrm{pH}=12$ was established. The suspension was decanted, washed, and the MNPs were separated by a permanent magnet and dried at room temperature. Thus, prepared magnetite nanoparticles $\left(\mathrm{Fe}_{3} \mathrm{O}_{4}\right)$ were oxidized to maghemite $\left(\gamma-\mathrm{Fe}_{2} \mathrm{O}_{3}\right)$ by exposing them to air and humidity, as described in [38]. Cuand Co-modified CFAZs were obtained by postsynthesis modification of the parent samples applying an incipient wetness impregnation technique. Solutions of $\mathrm{Cu}\left(\mathrm{NO}_{3}\right)_{2} \cdot 3 \mathrm{H}_{2} \mathrm{O}$ (pure for analysis, Valerus, Sofia, Bulgaria) and $\mathrm{Co}\left(\mathrm{NO}_{3}\right)_{2} \cdot 6 \mathrm{H}_{2} \mathrm{O}$ (pure for analysis, Valerus, Sofia, Bulgaria) were mixed with CFAZ samples in amounts corresponding to $6 \mathrm{wt} \%$ of $\mathrm{Cu}$ and Co loading. The impregnated samples were dried at ambient temperature, and the precursor salts were decomposed in air at $500{ }^{\circ} \mathrm{C}$ for $2 \mathrm{~h}$.

\subsection{Characterization of Non-Modified and Metal Oxide-Modified CFAZs}

The phase composition of CFAZ and modified samples were studied by X-ray diffraction (XRD) using a diffractometer Brucker D2 Phaser (Bucker Corporation, Karlsruhe, Germany) with $\mathrm{CuK} \alpha$-radiation and a Ni-filter. CFAZ morphology was observed by scanning electron microscopy (SEM) on a Carl Zeiss SMT SEM EVO LS25 microscope (Carl Zaiss AG, Oberkochen, Germany) with an EDAX Trident system. Surface characteristics of the samples were investigated through experimental nitrogen adsorption/desorption isotherms measured at $77 \mathrm{~K}$ using a volumetric adsorption analyzer Tristar II 3020 (Micromeritics Instrument Corporation, Gwinnett County, GA, USA). The parent and modified CFAZs were preliminarily degassed in a set-up FlowPrep 60 (Micromeritics, Instrument 
Corporation, USA) at $533 \mathrm{~K}$ for 16 hours under helium flow. BET specific surface area $\left(\mathrm{S}_{\mathrm{BET}}, \mathrm{m}^{2} / \mathrm{g}\right)$ was calculated by the multi-point Brunauer-Emmett-Teller (BET) model from the adsorption data in relative pressure $\mathrm{p} / \mathrm{p}_{0}$ range, corresponding to the monolayer formation. The mesopore size distribution functions were computed by the Barrett-Joyner-Helenda (BJH) model applied to the desorption branch of the isotherms. The size of micropores and the specific surface and volume described by them were derived by the t-plot model.

\subsection{Magnetite Nanoparticles Characterization}

X-ray powder diffraction patterns of MNPs were recorded by a Philips PW 1810/3710 diffractometer (Philips, Nederlands) with Bragg-Brentano parafocusing geometry, applying monochromatized $\mathrm{CuK}_{\alpha}$ $(\lambda=0.15418 \mathrm{~nm})$ radiation $(40 \mathrm{kV}, 35 \mathrm{~mA})$ and proportional counter.

The magnetic properties of the iron oxide nanoparticles were measured using a Quantum Design MPMS-5S superconducting quantum interference device (SQUID) magnetometer (Quantum Design Inc., USA). The dried samples were packed into gelatin capsules in vacuum grease. Zero-field-cooled-field-cooled (ZFC-FC) magnetization curves were obtained from $-268{ }^{\circ} \mathrm{C}$ to $25^{\circ} \mathrm{C}$. In ZFC mode, the samples were cooled in a nominally zero magnetic field (in practice, in about -1 Oe) from 25 to $-268^{\circ} \mathrm{C}$ and the magnetization was subsequently measured in a field of 10 Oe with increasing temperature. In FC mode, the sample was cooled in 10 Oe from 25 to $-268{ }^{\circ} \mathrm{C}$ and the magnetization was subsequently measured in the same field with increasing temperature. Hysteresis loops of dried samples were taken in fields between $\pm 50 \mathrm{kOe}$ at -268 and $25{ }^{\circ} \mathrm{C}$. The saturation magnetization (Ms) was defined as the value of the magnetization at $2 \mathrm{~T}$.

Mössbauer spectroscopic measurements were performed by a KFKI spectrometer (KFKI Production, Hungary), operating in constant acceleration mode with ${ }^{57} \mathrm{Co} / \mathrm{Rh}$ source (0.5 GBq). The positional parameters are related to the alpha-iron standard. The accuracy of these data is ca. $\pm 0.03 \mathrm{~mm} / \mathrm{s}$. In situ spectra were recorded at ambient $\left(27^{\circ} \mathrm{C}\right)$ and at liquid nitrogen $\left(-196{ }^{\circ} \mathrm{C}\right)$ temperatures. The following parameters of hyperfine interactions were extracted from the spectral components by computer fitting: isomer shift (IS), quadrupole splitting (QS), line widths (FW), and relative intensities of the components (RI).

\subsection{Heavy Metal Adsorption Tests}

The adsorption ability of nonmodified and metal oxide-modified CFAZs to retain $\mathrm{Cd}^{2+}$ - and $\mathrm{Pb}^{2+}$-ions was studied performing batch tests. Starting solutions of $\mathrm{Cd}\left(\mathrm{NO}_{3}\right)_{2} \cdot 2 \mathrm{H}_{2} \mathrm{O}$ (reagent grade, Macrochem, Ukraine) and $\mathrm{Pb}\left(\mathrm{NO}_{3}\right)_{2}$ (reagent grade, Macrochem, Ukraine) in distilled water were prepared with concentrations of $200 \mathrm{ppm} \mathrm{Cd}^{2+}$-ions and $100 \mathrm{ppm} \mathrm{Pb}^{2+}$-ions. A series of test solutions for both ions were prepared by consecutive dilution of the stock solutions. The experiments were conducted at $22 \pm 2{ }^{\circ} \mathrm{C}$ by immersing $0.02 \mathrm{~g}$ of CFAZs in $25 \mathrm{~mL}$ solutions containing the desired starting concentration of the heavy metal ions. The mixtures were agitated for $24 \mathrm{~h}$ in $50 \mathrm{~mL}$ plastic bottles using a tumbling mill and then filtered using filter papers. The adsorption isotherms were measured at $\mathrm{pH}=5.5$, and the effect of $\mathrm{pH}$ of the test solution on the heavy metal removal efficiency of the CFAZs was also studied in the $\mathrm{pH}$-interval from 1 to 8 . The exact initial and final concentrations of the heavy metal ions in the aqueous solutions were determined by a Fast Sequential Atomic Absorption Spectrometer AA240FS (Agilent, USA).

\subsection{Fenton Oxidation Tests}

The Fenton oxidation tests were performed toward methylene blue (MB, pure for analysis, Valerus, Sofia, Bulgaria) as a model contaminant by batch technique. Hydrogen peroxide was used as an oxidant adding $3 \mathrm{~mL}$ of $6 \% \mathrm{H}_{2} \mathrm{O}_{2}$ (Kupro, Bulgaria) to $25 \mathrm{~mL}$ solution of $\mathrm{MB}$ with an initial concentration of $20 \mathrm{mg} / \mathrm{L}$. The oxidation tests were performed using as catalysts $0.05 \mathrm{mg}$ of the parent and modified CFAZ at fixed $\mathrm{pH}=2.0$ and temperatures of 60 and $90^{\circ} \mathrm{C}$. The optical absorption was measured at $\lambda_{\max }=665 \mathrm{~nm}$ using optical glass cuvettes with $10 \mathrm{~mm}$ in length. 


\section{Results}

\subsection{Material Characterization}

Experimental X-ray diffractograms of the raw CFA, nonmodified and modified coal fly ash zeolites are plotted in Figure 1. The main crystalline phases observed in the CFA are quartz $\left(\alpha-\mathrm{SiO}_{2}\right)$, anorthite $\left(\mathrm{CaAl}_{2} \mathrm{Si}_{2} \mathrm{O}_{8}\right)$, magnetite $\left(\gamma-\mathrm{Fe}_{3} \mathrm{O}_{4}\right)$, and hematite $\left(\alpha-\mathrm{Fe}_{2} \mathrm{O}_{3}\right)$. X-ray diffraction pattern of nonmodified zeolite sample, denoted further as CFAZ, reveals a highly crystalline structure typical for zeolite $\mathrm{Na}-\mathrm{X}$, which is evidenced comparing to a reference $X$-ray diffractogram of zeolite Na-X. Individual reflexes of the sodalite phase (SOD), which often accompanies zeolite $X$ during its crystallization at temperatures of 70-90 ${ }^{\circ} \mathrm{C}$ [8], are also found. Reflexes of the iron oxide phases transferred from the raw fly ash were not detected on the X-ray diffractogram of CFAZ. On the X-ray diffractogram of the MNP-loaded CFAZ (MNP-CFAZ), the main line of $\gamma-\mathrm{Fe}_{2} \mathrm{O}_{3}$ is observed. The impregnation of the parent zeolite sample with copper (Cu-CFAZ) and cobalt (Co-CFAZ) salts leads to the appearance of barely noticeable characteristic lines of their corresponding oxides, $\mathrm{CuO}$ and $\mathrm{Co}_{3} \mathrm{O}_{4}$, on the $\mathrm{X}$-ray diffraction patters of the modified CFAZs. All of the samples, after their modification with metal oxides, retain the structure of the zeolite $\mathrm{Na}-\mathrm{X}$, as can be seen from its clearly expressed characteristic lines on the experimental diffraction patterns.

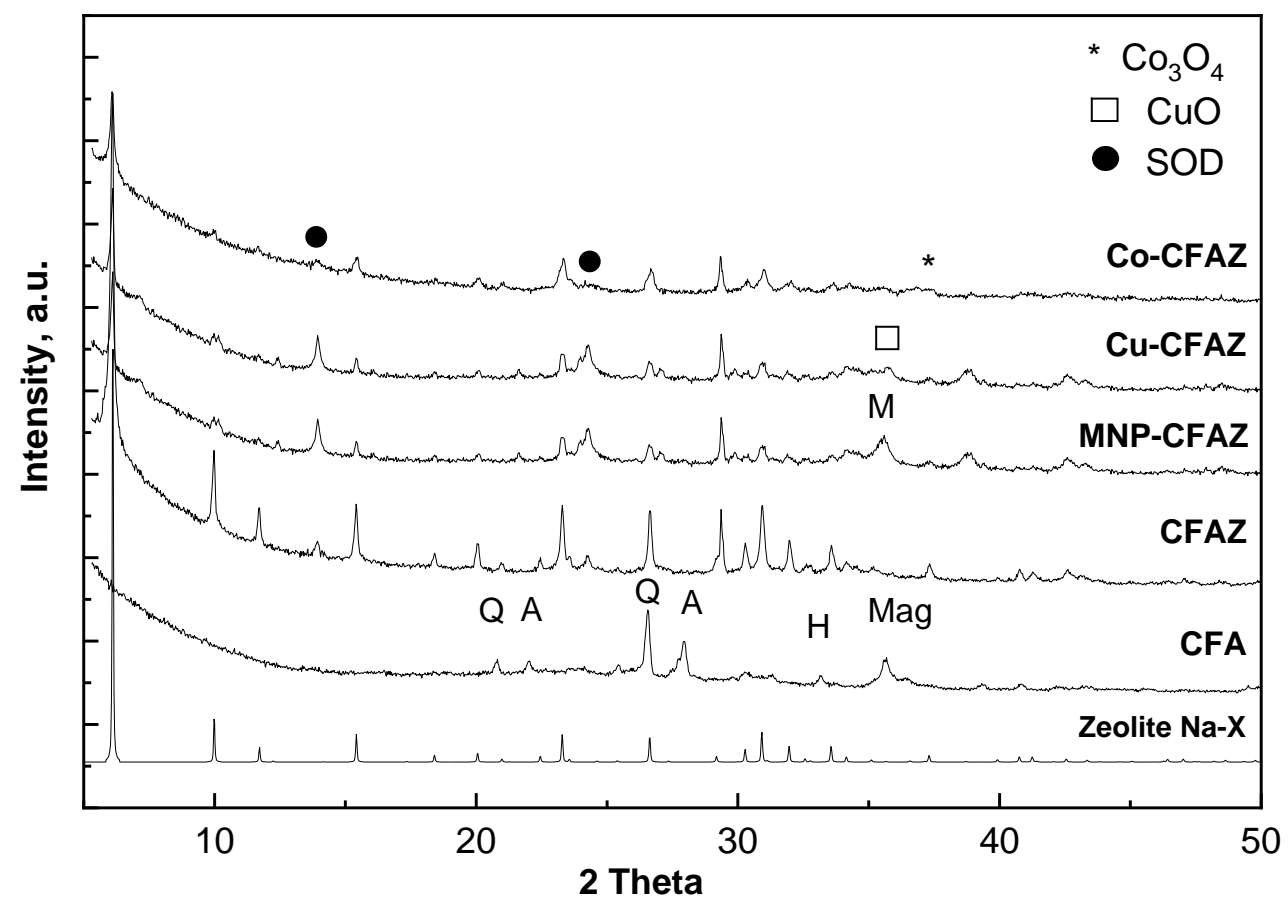

Figure 1. Experimental $X$-ray diffraction patterns of a nanocrystalline zeolite of Na-X type (CFAZ) and modified CFAZ: Q—quartz, A—anorthite, $\mathrm{H}$-hematite, Mag-magnetite, $\mathrm{M}$-maghemite. A referent $\mathrm{X}$-ray diffractogram of zeolite $\mathrm{Na}-\mathrm{X}$ is plotted for comparison.

Typical SEM images of parent and modified CFAZs are presented in Figure 2. SEM analyses reveal the nanocrystalline morphology of all the coal fly ash zeolites due to ultrasonic agitation. The modified CFAZs are characterized by more agglomerated morphology as compared to the parent CFAZ. 


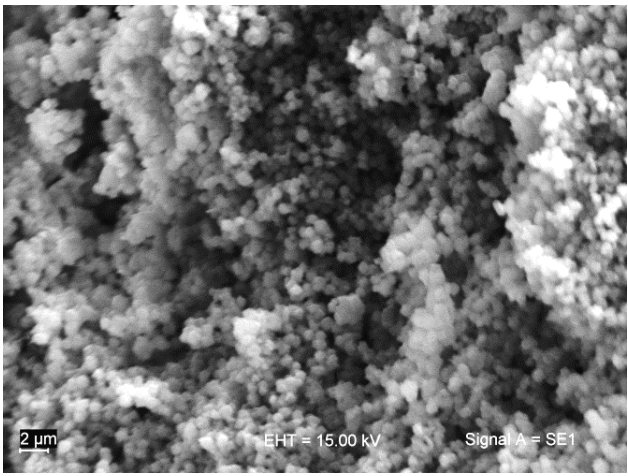

(a)

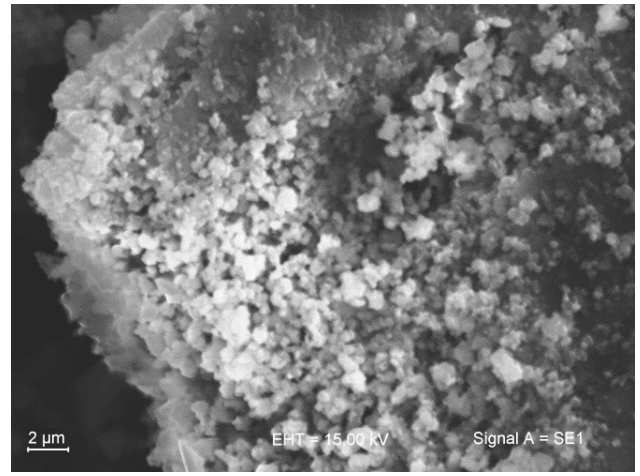

(b)

Figure 2. SEM images of (a) CFAZ; (b) magnetic nanoparticles (MNP)-CFAZ.

The experimental $\mathrm{N}_{2}$-isotherms of adsorption and desorption for the nonmodified and metal oxide-modified zeolite samples are plotted in Figure 3a. The $\mathrm{N}_{2}$-isotherms for modified samples are shifted toward lower $\mathrm{N}_{2}$-adsorbed quantities in the studied relative pressure range $\mathrm{p} / \mathrm{p}_{0}$ compared to the $\mathrm{N}_{2}$-isotherm of the nonmodified sample. The isotherms of the all studied zeolite specimens can be classified as type IV with H3 hysteresis loops (IUPAC, 1985), typical for materials with mixed micromesoporous textures.

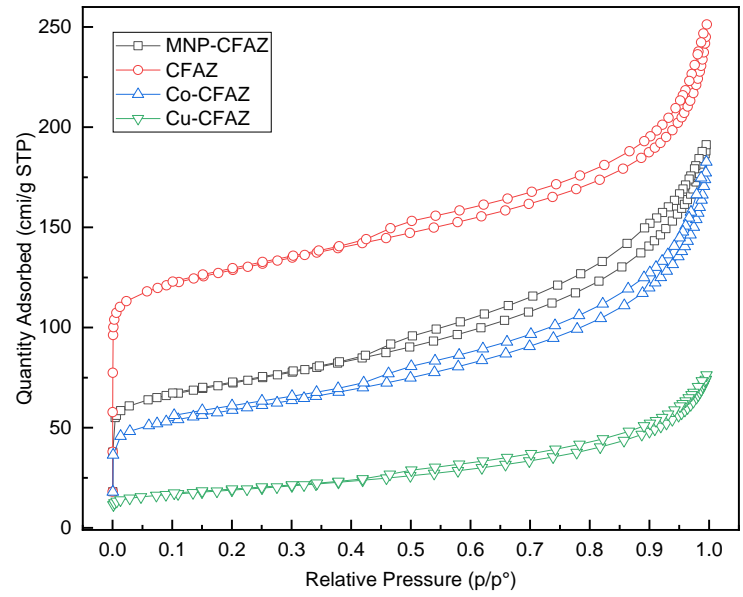

(a)

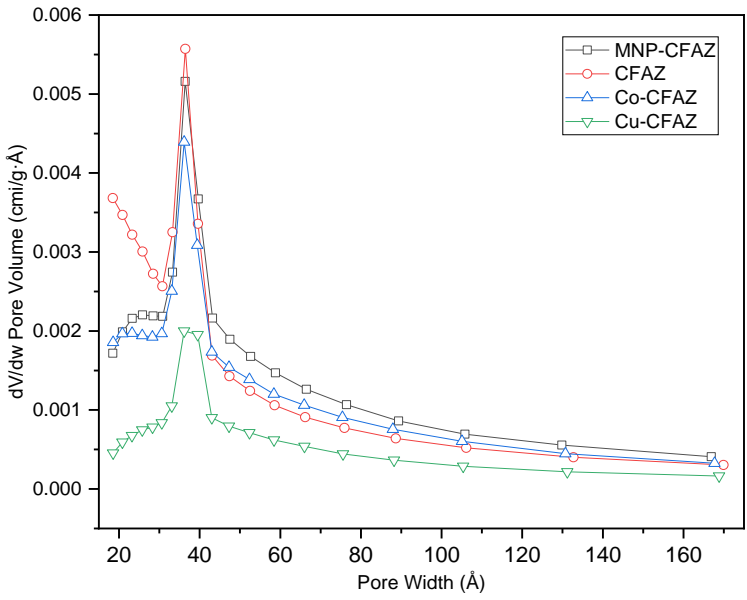

(b)

Figure 3. Results from $\mathrm{N}_{2}$ adsorption/desorption analyses: (a) experimental $\mathrm{N}_{2}$-adsorption/desorption isotherms; (b) BJH-pore size distribution functions.

CFAZ is characterized by high BET specific surface value $\left(\mathrm{S}_{\mathrm{BET}}, \mathrm{m}^{2} / \mathrm{g}\right)$, revealing a significant yield of the zeolite phase. For the metal oxide-modified samples, $\mathrm{S}_{\mathrm{BET}}$ significantly decreases as the lowest values are obtained for $\mathrm{Cu}-\mathrm{CFAZ}$. The lowering of the specific surface values described by micropores $\left(\mathrm{S}_{\text {micro }}, \mathrm{m}^{2} / \mathrm{g}\right)$ indicates that the metal oxide particles fill the micropores of the modified samples, and the decrease in the outer surface of the zeolite particles $\left(S_{\text {extern }}, \mathrm{m}^{2} / \mathrm{g}\right)$ corresponds to their agglomeration upon modification. The significant drop in the values for the volume described by the micropores $\left(\mathrm{V}_{\text {micro }}, \mathrm{cm}^{3} / \mathrm{g}\right)$ for modified CFAZs confirms their filling with metal oxide particles. The volume described by the mesopores $\left(\mathrm{V}_{\text {meso }}, \mathrm{cm}^{3} / \mathrm{g}\right)$ keeps commensurate values for the parent and derived coal fly ash zeolites, except $\mathrm{Cu}-\mathrm{FAZ}$, at which $\mathrm{V}_{\text {meso }}$ is profoundly reduced. The total volume of pores $\left(\mathrm{V}_{\text {total }}, \mathrm{cm}^{3} / \mathrm{g}\right)$ corresponds to the sum of $\mathrm{V}_{\text {micro }}$ and $\mathrm{V}_{\text {meso }}$ values. The average micro- and mesopore sizes are comparable for all the studied samples. The mesopore size distribution functions 
obtained by BJH-model are plotted in Figure 3b. It is observed that the biggest share for all the CFAZs belongs to the pores with diameters around $40 \AA$.

The calculated surface properties from the model studies of the experimental isotherms are summarized in Table 1.

Table 1. Surface properties of nonmodified and modified CFAZs.

\begin{tabular}{ccccccccc}
\hline Sample & $\begin{array}{c}\mathbf{S}_{\text {BET, }} \\
\mathbf{m}^{\mathbf{2}} / \mathbf{g}\end{array}$ & $\begin{array}{c}\mathbf{S}_{\text {micror }} \\
\mathbf{m}^{\mathbf{2}} / \mathbf{g}\end{array}$ & $\begin{array}{c}\mathbf{S}_{\text {extern, }} \\
\mathbf{m}^{\mathbf{2}} \mathbf{g}\end{array}$ & $\begin{array}{c}\mathbf{V}_{\text {total, }} \\
\mathbf{c m}^{\mathbf{3}} / \mathbf{g}\end{array}$ & $\begin{array}{c}\mathbf{V}_{\text {micror }} \\
\mathbf{c m}^{\mathbf{3}} / \mathbf{g}\end{array}$ & $\begin{array}{c}\mathbf{V}_{\text {mesor }} \\
\mathbf{c m}^{\mathbf{3}} \mathbf{g}\end{array}$ & $\begin{array}{c}\mathbf{d}_{\text {micror }} \\
\AA\end{array}$ & $\begin{array}{c}\mathbf{d}_{\text {mesor }} \\
\mathbf{A}\end{array}$ \\
\hline CFAZ & 486 & 334 & 166 & 0.307 & 0.133 & 0.174 & 14 & 42 \\
MNP-CFAZ & 264 & 137 & 127 & 0.246 & 0.057 & 0.189 & 14 & 49 \\
Cu-CFAZ & 67 & 20 & 47 & 0.080 & 0.009 & 0.071 & 13 & 51 \\
Co-CFAZ & 213 & 96 & 117 & 0.200 & 0.040 & 0.160 & 13 & 48 \\
\hline
\end{tabular}

$\mathrm{S}_{\mathrm{BET}}$-specific surface area; $\mathrm{V}_{\text {total }}, \mathrm{V}_{\text {micro }}, \mathrm{V}_{\text {meso }}$ - total pore volume and internal volume described by micro and mesopores, correspondingly; $\mathrm{d}_{\text {micro }}, \mathrm{d}_{\text {meso }}$-average micro- and mesopore sizes.

X-ray driffraction and Mössbauer spectra of the MNPs used in the modification of CFAZ are presented in Figure 4.

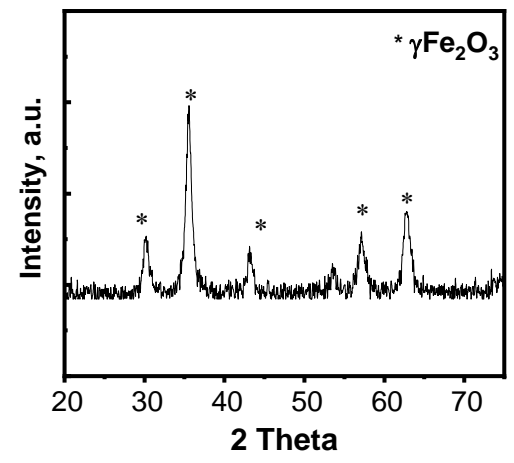

(a)

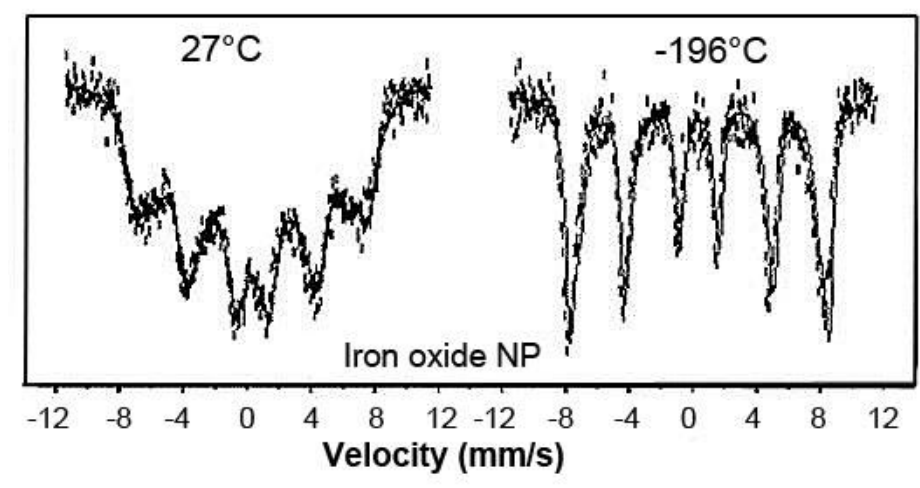

(b)

Figure 4. X-ray diffraction pattern (a) and Mössbauer spectra (b) of the MNPs.

The XRD patterns of the nanosized iron oxide particles show wider reflections typical of small nanoparticles (Figure 4a). The presence of two magnetic phases of magnetite $\left(\gamma-\mathrm{Fe}_{3} \mathrm{O}_{4}\right)$ and maghemite $\left(\gamma-\mathrm{Fe}_{2} \mathrm{O}_{3}\right)$ could be supposed as their crystalline structure is very similar. The difference is that the maghemite has a lower bulk saturation magnetization value than magnetite ( $92 \mathrm{emu} / \mathrm{g}$ for magnetite, $\sim 76 \mathrm{emu} / \mathrm{g}$ for maghemite). Magnetite $\gamma-\mathrm{Fe}_{3} \mathrm{O}_{4}$ and maghemite $\gamma-\mathrm{Fe}_{2} \mathrm{O}_{3}$ can be differentiated by the X-ray diffraction method based on the detailed profile analysis of (511) reflection at around $572 \theta^{\circ}$. The method is based on the small shift of (511) reflection of maghemite toward higher $2 \theta^{\circ}$ values compared to magnetite when the FWHM (full widths at half maximum) of the two compounds makes it possible to differentiate their overlap [39]. However, the distinction between the two magnetic phases by X-ray diffraction is not unambiguous. The particle size calculated by the Sherrer equation, applying the profile fitting method, is $10 \mathrm{~nm}$.

Mössbauer spectroscopic investigations support the predominant formation of maghemite nanoparticles. Comparison of Mössbauer spectra recorded at 27 and $-196{ }^{\circ} \mathrm{C}$ clearly shows the dominant presence of superparamagnetic maghemite nanoparticles (Figure $4 \mathrm{~b}$ ). In the first approach, the magnetically split parts of spectra were decomposed to two sextets in correspondence with the two different possible coordinations of iron ions in maghemite (e.g., tetrahedral and octahedral; Table 2). 
Table 2. Mössbauer parameters of the iron oxide nanoparticles.

\begin{tabular}{|c|c|c|c|c|c|c|c|c|c|}
\hline \multirow{2}{*}{ Sample } & \multicolumn{4}{|c|}{$300 \mathrm{~K}$} & \multicolumn{5}{|c|}{$77 \mathrm{~K}$} \\
\hline & Comp & IS & QS & MHF & RI & IS & QS & MHF & RI \\
\hline $\begin{array}{l}\text { Iron } \\
\text { oxide }\end{array}$ & Sext (1) & 0.35 & - & 45.6 & 24 & 0.44 & - & 50.5 & 54 \\
\hline MNP & Sext (2) & 0.37 & - & 38.5 & 76 & 0.41 & - & 46.9 & 46 \\
\hline
\end{tabular}

The small size of the particles is reflected in the superparamagnetic behavior, i.e., a decrease of the measuring temperature results in the increase of the extent of magnetic ordering-the presence of antiferromagnetic sextets is more pronounced in the $-196{ }^{\circ} \mathrm{C}$ spectra.

Magnetic properties of the synthesized iron oxide nanoparticles were proved by magnetization measurements (Figure 5). The saturation magnetization $\left(M_{s}\right)$ for our maghemite nanoparticles is $57 \mathrm{emu} / \mathrm{g}$, which is lower than that of the bulk maghemite $(75 \mathrm{emu} / \mathrm{g})$ but is in accordance with the $\mathrm{M}_{\mathrm{s}}$ values of $10 \mathrm{~nm}$ oxidized magnetite nanoparticles ranging from $52-62 \mathrm{emu} / \mathrm{g}$ in the literature [39].

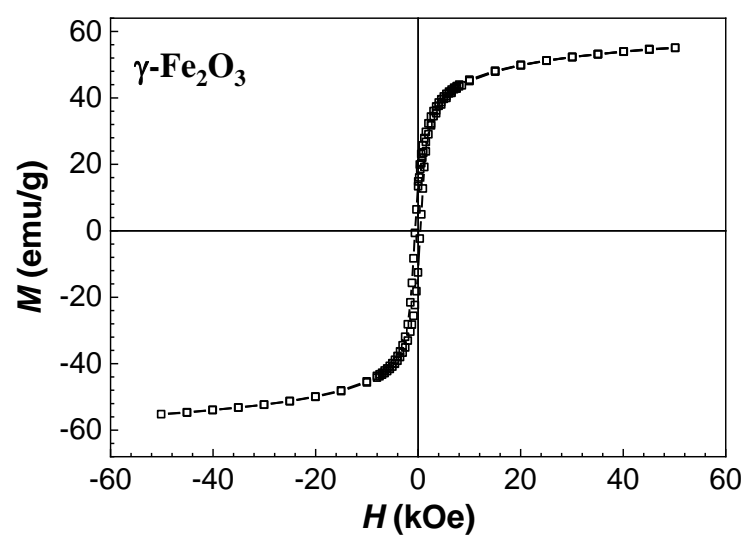

Figure 5. Magnetic properties of iron oxide nanoparticles.

\subsection{Adsorption Studies of $\mathrm{Cd}^{2+}$-and $\mathrm{Pb}^{2+}$-ions onto Nonmodified and Modified Coal Fly Ash Zeolites}

\subsubsection{Equilibrium Adsorption Studies}

The removal efficiency $\mathrm{R}(\%)$ of coal fly ash zeolites toward $\mathrm{Cd}^{2+}$ - and $\mathrm{Pb}^{2+}{ }_{\text {-ions }}$ was calculated by the following equation:

$$
\mathrm{R}=\frac{\left(C_{0}-C_{e}\right)}{C_{0}} \cdot 100, \%
$$

where $C_{0}$ is the initial concentration of $\mathrm{Cd}^{2+}$ - or $\mathrm{Pb}^{2+}$ - ions in the tested solutions; $C_{e}$ is the equilibrium concentration of $\mathrm{Cd}^{2+}$ - or $\mathrm{Pb}^{2+}$ - ions in the liquid phase after the adsorption, $\mathrm{mg} / \mathrm{L}$.

The dependence of the removal efficiency of the studied adsorbents on the initial concentration of the heavy metal ions in the tested solutions is demonstrated in Figure 6.

All of the studied adsorbents reveal strong efficiency to remove $\mathrm{Cd}^{2+}$-ions from water at concentration levels up to $50 \mathrm{mg} \mathrm{Cd}{ }^{2+} / \mathrm{L}$. By increasing the concentration of cadmium ions in the stock solution, their removal efficiency decreases but retains significant values for CFAZ and MNP-CFAZ, while for Cu-CFAZ and Co-CFAZ R-values drop down almost by half at starting concentration levels of $150-200 \mathrm{mgCd}^{2+} / \mathrm{L}$. All studied adsorbents show high efficiency toward the removal of $\mathrm{Pb}^{2+}{ }_{\text {-ions }}$ from aqueous media and maintained high R-values up to $100 \mathrm{mg} \mathrm{Pb}{ }^{2+} / \mathrm{L}$. Cu-CFAZ, and Co-CFAZs exhibit a higher adsorption capacity for $\mathrm{Pb}^{2+}$ than for $\mathrm{Cd}^{2+}$, with the retention efficiency of lead ions being higher compared to CFAZs and MNP-CFAZs. Coal ash zeolites modified with copper and cobalt oxides completely retain $\mathrm{Pb}^{2+}$-ions from the treated aqueous solutions at starting concentration values of $100 \mathrm{mgPb}^{2+} / \mathrm{L}$. 


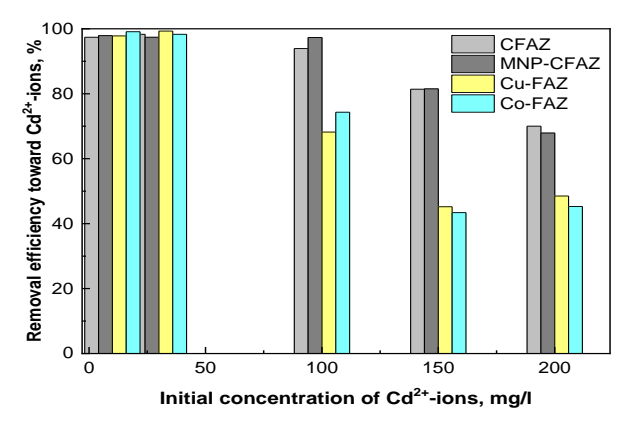

(a)

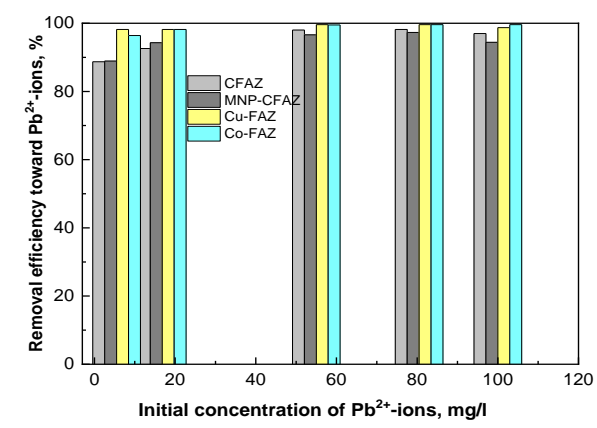

(b)

Figure 6. Removal efficiency of nonmodified and modified coal fly ash zeolites toward (a) $\mathrm{Cd}^{2+}$-ions; (b) $\mathrm{Pb}^{2+}$-ions.

The equilibrium adsorption capacities $\mathrm{q}_{\mathrm{e}}(\mathrm{mg} / \mathrm{g})$ of the heavy metal ions on the studied adsorbents were calculated according to the following equation:

$$
\mathrm{q}_{\mathrm{e}}=\frac{\left(C_{0}-C_{e}\right)}{m_{\mathrm{s}}} \cdot V, \%
$$

where $V$ is the volume of the tested solution, $\mathrm{L} ; \mathrm{m}_{\mathrm{s}}$ - the weight of the used adsorbent, $\mathrm{g}$.

In order to clarify the mechanism of capturing cadmium ions by the studied adsorbents, the experimental data were described by different thermodynamic models.

The adsorption of bivalent metal ions from water onto natural, synthetic, and coal ash zeolites is usually described with a good correlation by the thermodynamic models of Langmuir and Freundlich [40,41]. A number of studies have revealed that upon adsorption of bivalent heavy metals from iron particles or iron oxide phases, Temkin's isotherm shows a good correlation with the experiment [42].

Langmuir model assumes that adsorption occurs by the formation of a monolayer of the adsorbate molecules on the homogeneous surface of the adsorbent. It is described by the following equation:

$$
\mathrm{q}_{\mathrm{e}}=\frac{Q_{\mathrm{sat}} K_{L} C_{e}}{1+K_{L} C_{e}}
$$

where $Q_{\text {sat }}$ is the monolayer adsorption capacity, $\mathrm{mg} / \mathrm{g} ; K_{L}$-Langmuir constant related to adsorption capacity obeyed by the free adsorption energy, $\mathrm{L} / \mathrm{mg}$. The linear form of Equation (3) is presented as follows:

$$
\frac{C_{e}}{q_{\mathrm{e}}}=\frac{1}{K_{L} Q_{s a t}}+\frac{C_{e}}{Q_{s a t}}
$$

When multi-layer adsorption takes place on a heterogeneous surface, the process is described by the Freundlich model:

$$
\mathrm{q}_{\mathrm{e}}=\mathrm{K}_{\mathrm{f}} C_{e}^{1 / \mathrm{n}}
$$

where $\mathrm{K}_{\mathrm{f}}$ is the Freundlich constant related to the adsorption capacity, $\mathrm{L} / \mathrm{g}$; $\mathrm{n}$-adsorption intensity, describing the heterogeneity of the adsorbate sites.

Langmuir-Freundlich isotherm model is valid when monolayer adsorption takes place on heterogeneous surfaces. It is described by

$$
\mathrm{q}_{\mathrm{e}}=\frac{\mathrm{Q}_{\mathrm{sat}}\left(\mathrm{K}_{\mathrm{L}} C_{e}\right)^{\mathrm{n}}}{\left(\mathrm{K}_{\mathrm{L}} C_{e}\right)^{\mathrm{n}}+1}
$$


The Temkin isotherm model is relevant to the adsorption data when indirect interactions between the adsorbent and adsorbate take place, accompanied by a linear decrease in the adsorption free energy with an increase of the surface coverage. It is expressed by the following equation:

$$
\mathrm{q}_{\mathrm{e}}=\left(R \frac{T}{b}\right) \ln A_{t}+\left(R \frac{T}{b}\right) \ln C_{e}
$$

where $b$ is the Temkin constant related to the heat of adsorption, $\mathrm{J} / \mathrm{mol} ; A_{t}$ is the Temkin isotherm constant, $\mathrm{L} / \mathrm{g} ; \mathrm{R}$ - universal gas constant, $\mathrm{J} / \mathrm{K}$ mol; $\mathrm{T}$-absolute temperature, $\mathrm{K}$.

The models applied and the results obtained for their parameters, together with the values for the correlation coefficients $\left(\mathrm{R}^{2}\right)$, are summarized in Table 3. The adsorption isotherms of the $\mathrm{Cd}^{2+}$-ions for all tested samples are described with the highest correlation coefficient by the linear Langmuir model. The experimental isotherms for $\mathrm{Cd}^{2+}$-adsorption onto parent and modified CFAZs and their linear and nonlinear Langmuir fittings are plotted in Figure 7.

Table 3. Results from the thermodynamic model studies of the experimental isotherms for adsorption of $\mathrm{Cd}^{2+}$-ions.

\begin{tabular}{|c|c|c|c|c|c|}
\hline \multirow{2}{*}{ Thermodynamic Models } & Model & \multirow{2}{*}{ CFAZ } & \multirow{2}{*}{ MNP-CFAZ } & \multirow{2}{*}{ Cu-CFAZ } & \multirow{2}{*}{ Co-CFAZ } \\
\hline & Parameters & & & & \\
\hline \multirow{3}{*}{ Langmuir linear } & $\mathrm{Q}_{\text {sat }}, \mathrm{mg} / \mathrm{g}$ & 170.1 & 163.7 & 99.8 & 93.9 \\
\hline & $\mathrm{K}_{\mathrm{L}}, \mathrm{L} / \mathrm{mg}$ & 0.3 & 0.4 & 0.3 & 0.4 \\
\hline & $\mathrm{R}^{2}$ & 0.992 & 0.995 & 0.909 & 0.922 \\
\hline \multirow{3}{*}{ Langmuir nonlinear } & $\mathrm{Q}_{\text {sat }}, \mathrm{mg} / \mathrm{g}$ & 159.1 & 157.4 & 93.2 & 92.5 \\
\hline & $\mathrm{K}_{\mathrm{L}}, \mathrm{L} / \mathrm{mg}$ & 0.5 & 0.7 & 1.6 & 1.4 \\
\hline & $\mathrm{R}^{2}$ & 0.978 & 0.928 & 0.825 & 0.886 \\
\hline \multirow{3}{*}{ Freundlich } & $\mathrm{K}_{\mathrm{f}}, \mathrm{mg} / \mathrm{g}$ & 52.9 & 60.2 & 35.7 & 38.9 \\
\hline & $\mathrm{n}$ & 3.4 & 4.0 & 4.4 & 4.9 \\
\hline & $\mathrm{R}^{2}$ & 0.903 & 0.781 & 0.851 & 0.820 \\
\hline \multirow{4}{*}{ Langmuir-Freundlich } & $\mathrm{Q}_{\text {sat }}, \mathrm{mg} / \mathrm{g}$ & 161.8 & 139.7 & \multirow{4}{*}{ - } & 93.0 \\
\hline & $\mathrm{K}_{\mathrm{L}}, \mathrm{L} / \mathrm{mg}$ & 0.5 & 21.5 & & 1.3 \\
\hline & $\mathrm{n}$ & 1.0 & 14.4 & & 0.94 \\
\hline & $\mathrm{R}^{2}$ & 0.978 & 0.953 & & 0.886 \\
\hline \multirow{4}{*}{ Temkin } & $\mathrm{b}$ & 88.5 & 94.3 & 204.3 & 209.7 \\
\hline & $\mathrm{RT} / \mathrm{b}$ & 27.7 & 26.0 & 12.0 & 11.7 \\
\hline & $A_{t}, L / g$ & 7.1 & 0.8 & 35.2 & 39.8 \\
\hline & $\mathrm{R}^{2}$ & 0.975 & 0.874 & 0.846 & 0.864 \\
\hline
\end{tabular}




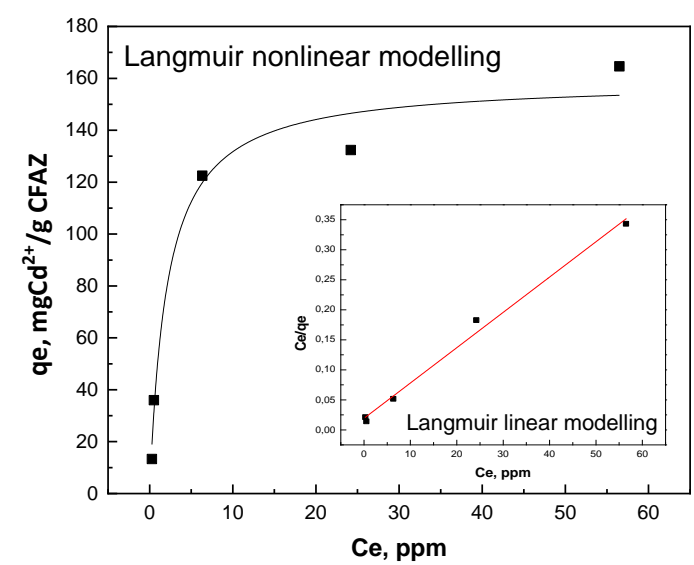

(a)

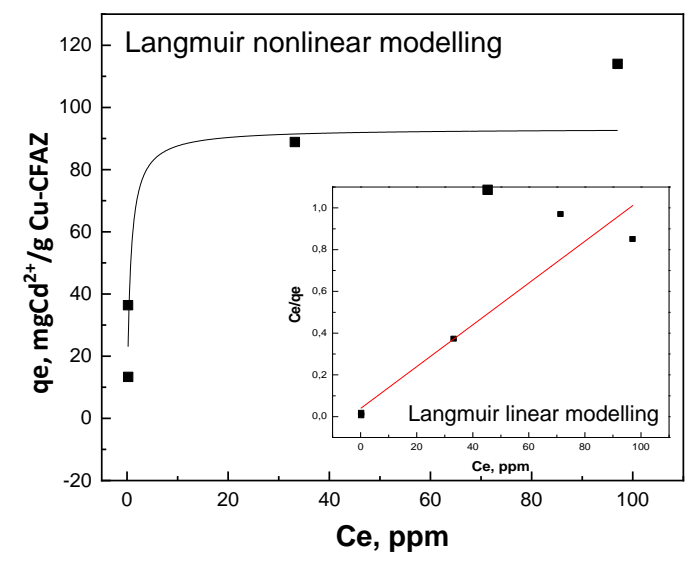

(c)

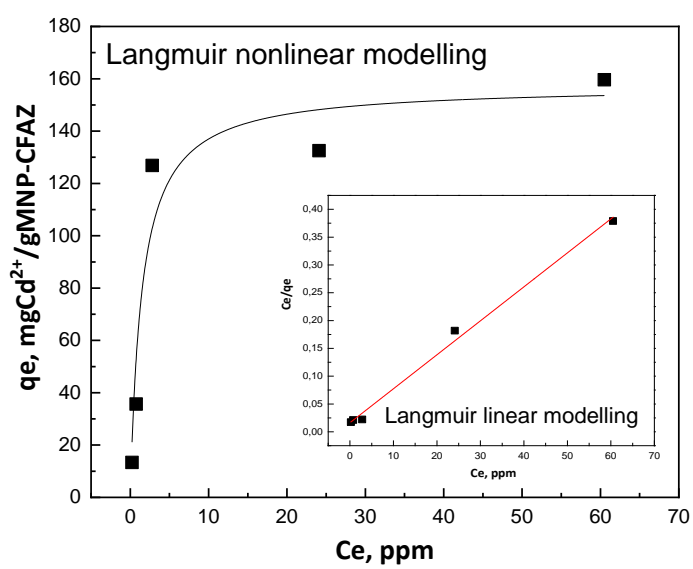

(b)

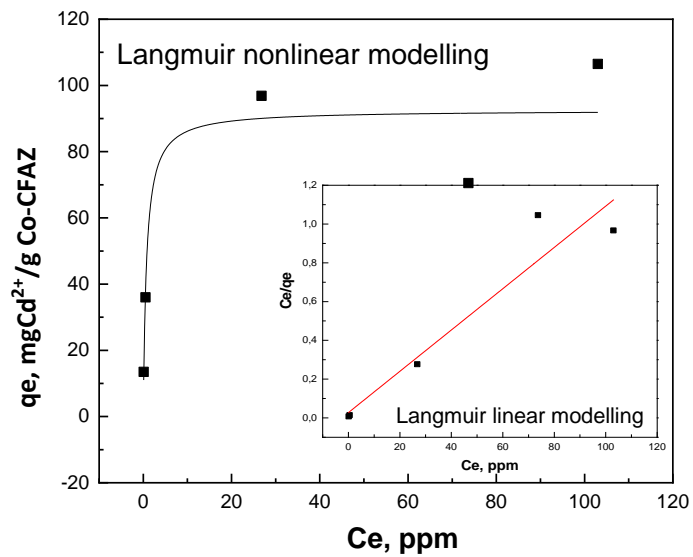

(d)

Figure 7. Experimental isotherms and Langmuir linear and nonlinear fit for $\mathrm{Cd}^{2+}$-ions adsorption onto nonmodified and modified CFAZ: (a) CFAZ; (b) MNP-CFAZ; (c) Cu-CFAZ; (d) Co-CFAZ.

\subsection{2. $\mathrm{pH}-$ Dependence of Heavy Metal Adsorption onto Nonmodified and Modified CFAZs}

The dependence of the adsorption efficiency of CFAZs and MNP-CFAZs toward $\mathrm{Cd}^{2+}{ }_{-}$and $\mathrm{Pb}^{2+}$-ions on the $\mathrm{pH}$ of the test solutions is demonstrated in Figure 8. In strongly acidic media $(\mathrm{pH}=1-2)$, MNP-CFAZ exhibits poor adsorption capacity for $\mathrm{Cd}^{2+}$-ions, while the unmodified sample does not retain them at all (Figure $8 \mathrm{a})$. By increasing the $\mathrm{pH}$ to neutral values $(\mathrm{pH}=6.5-7.5)$, the adsorption capacity of both zeolites increases: at about $\mathrm{pH}=3$, it is higher for CFAZs, while at $\mathrm{pH}=5.0-7.5$, the more effective is MNP-CFAZs. Regarding the removal of $\mathrm{Pb}^{2+}$-ions, both samples reveal from moderate ( $\mathrm{pH}=1.0-2.0)$ to significant retaining capacities $(\mathrm{pH}=2.5-3.5)$, as the CFAZ is more effective than the MNP-CFAZ in the region of strong acidity ( $\mathrm{pH}=1.0-3.5$; Figure $8 \mathrm{~b}$ ). In the low acidic to neutral $\mathrm{pH}$ values, higher retaining efficiency of $\mathrm{Pb}^{2+}$-ions was measured for the MNP-CFAZ. 


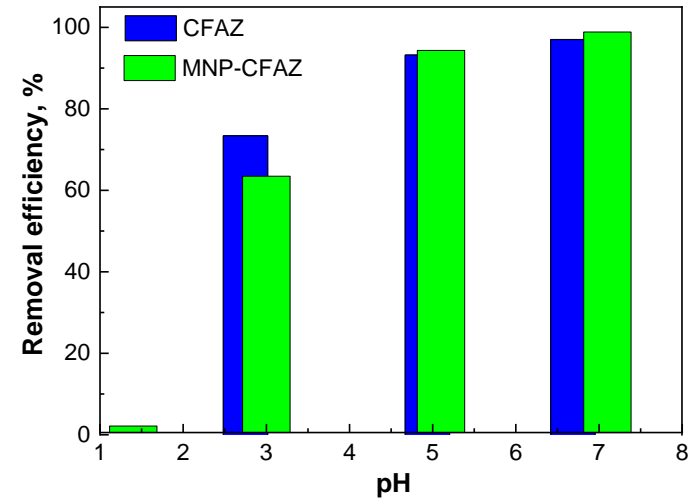

(a)

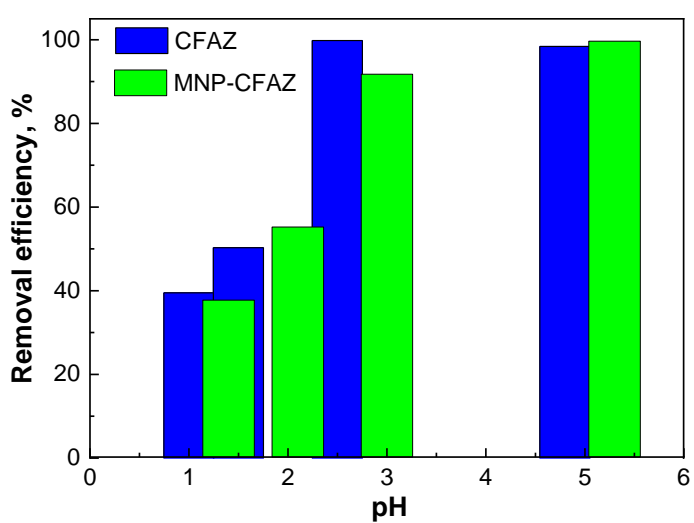

(b)

Figure 8. Effect of $\mathrm{pH}$ values on the adsorption efficiency of CFAZ and MNP-CFAZ: (a) toward $\mathrm{Cd}^{2+}$-ions; (b) toward $\mathrm{Pb}^{2+}$-ions.

\subsubsection{Heterogeneous Fenton Oxidation of Methylene Blue Using Nonmodified and Modified CFAZ}

The efficiency of the heterogeneous oxidative degradation $(D, \%)$ of MB in the presence of CFAZs and modified CFAZs is calculated by the following equation:

$$
D=\frac{C_{M B, 0}-C_{M B, \tau}}{C_{M B, 0}} \cdot 100, \%
$$

where $C_{M B, 0}$ and $C_{M B, \tau}$ are the initial and the current $M B$ concentrations, $\mathrm{mg} / \mathrm{L}$.

The efficiency of the Fenton oxidation degradation of $\mathrm{MB}$ measured at $90{ }^{\circ} \mathrm{C}$ and $60{ }^{\circ} \mathrm{C}$ is plotted in Figure 9. At higher temperatures, total oxidation of $\mathrm{MB}$ is achieved in less than $25 \mathrm{~min}$, as all tested samples exhibit high catalytic activity in the Fenton oxidation process (Figure 9a). It can be noted that the nonmodified CFAZ exhibits the highest catalytic activity with the progress of the oxidation process, while the Co-CFAZ is the least active. However, when the temperature is lowered to $60{ }^{\circ} \mathrm{C}$, the modified specimens exhibit higher catalytic activity than the parent CFAZ, with the highest Fenton oxidation rate recorded at the MNP-CFAZ (Figure 9b).

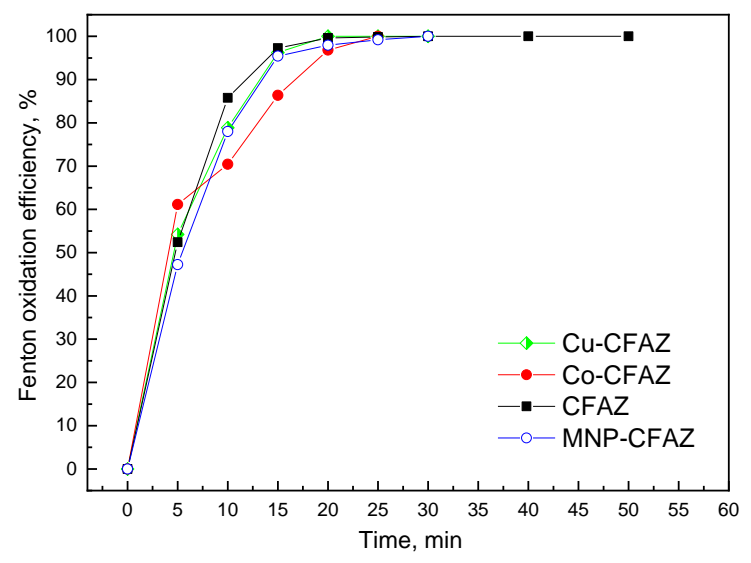

(a)

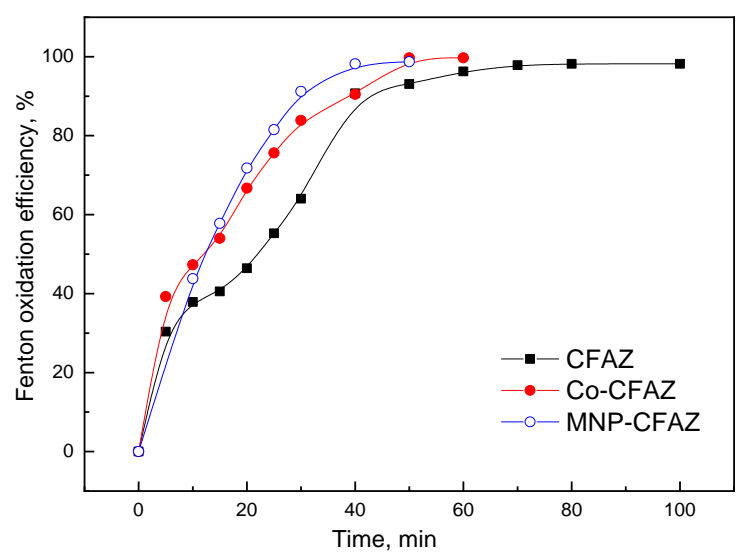

(b)

Figure 9. Fenton oxidation of $\mathrm{MB}$ in the presence of CFAZ and modified CFAZ: (a) kinetic curves at $90^{\circ} \mathrm{C}$; (b) kinetic curves at $60^{\circ} \mathrm{C}$. 
The experimental results were described, applying the pseudo first-(Equation (9)) and second-order (Equation (10)) kinetic models. The linear forms of the model equation used are as follows:

$$
\begin{gathered}
-\ln \frac{C_{M B, \tau}}{C_{M B, 0}}=k_{1} \tau \\
\frac{\tau}{C_{M B, \tau}}=\frac{1}{k_{2} C_{M B, 0}}+\frac{\tau}{C_{M B, 0}}
\end{gathered}
$$

where $k_{1}$ and $k_{2}$ are the reaction rate constants for the kinetic models of the pseudo first- and second-order, correspondingly, $\mathrm{min}^{-1} ; \tau$ is the reaction time, $\mathrm{min}$.

The impact of the catalyst amount on the oxidation process was studied previously [33].

The obtained results for the calculated kinetic constants and the oxidation reaction half-life $\tau_{1 / 2}$ for the Fenton oxidation of $\mathrm{MB}$ at $90{ }^{\circ} \mathrm{C}$ are summarized in Table 4 .

Table 4. Kinetic constants and oxidation reaction half-life of the Fenton oxidation process of methylene blue onto nonmodified and metal oxide modified CFAZs.

\begin{tabular}{ccccccc}
\hline \multirow{2}{*}{ Sample } & \multicolumn{3}{c}{ Pseudo First Order } & \multicolumn{3}{c}{ Pseudo Second Order } \\
\cline { 2 - 7 } & $\mathbf{K}_{\mathbf{1}, \mathbf{m i n}^{\mathbf{- 1}}}$ & $\boldsymbol{\tau}_{\mathbf{1} \mathbf{2},} \mathbf{~ m i n}^{\mathbf{- 1}}$ & $\mathbf{R}^{\mathbf{2}}$ & $\mathbf{K}_{\mathbf{2}}, \mathbf{M}^{-\mathbf{1}} \mathbf{m i n}^{\mathbf{- 1}}$ & $\boldsymbol{\tau}_{\mathbf{1} \mathbf{2}, \mathbf{m i n}^{-\mathbf{1}}}$ & $\mathbf{R}^{\mathbf{2}}$ \\
\hline CFAZ & 0.277 & 2.50 & 0.982 & 3.154 & 0.016 & 0.979 \\
MNP-CFAZ & 0.203 & 3.41 & 0.987 & 2.946 & 0.017 & 0.975 \\
Cu-CFAZ & 0.213 & 3.25 & 0.954 & 2.819 & 0.018 & 0.993 \\
Co-CFAZ & 0.159 & 4.36 & 0.945 & 3.247 & 0.015 & 0.973 \\
\hline
\end{tabular}

The regression coefficient values $\left(R^{2}\right)$ reveal that the degradation kinetics of MB is more accurately described by the pseudo first-order kinetic equation when CFAZ and MNP-CFAZ are used as catalysts, and by the pseudo second-order when the oxidation is catalyzed by Cu-CFAZ and Co-CFAZ. The calculations of the experimental results for degradation of MB by Fenton reaction onto CFAZ and modified CFAZ catalysts by applying the pseudo first- and second-order kinetic equations are demonstrated in Figure 10. 


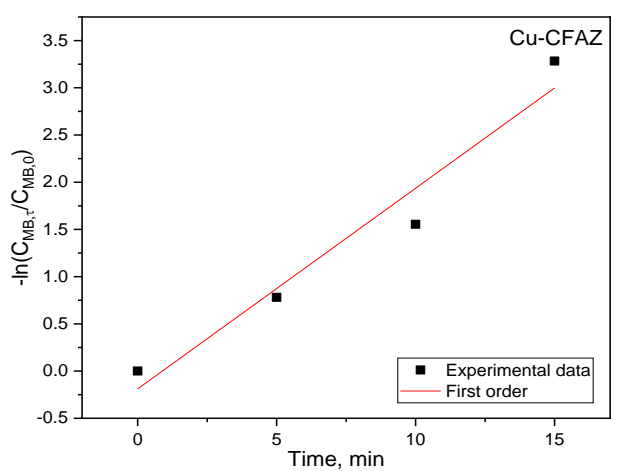

(a)

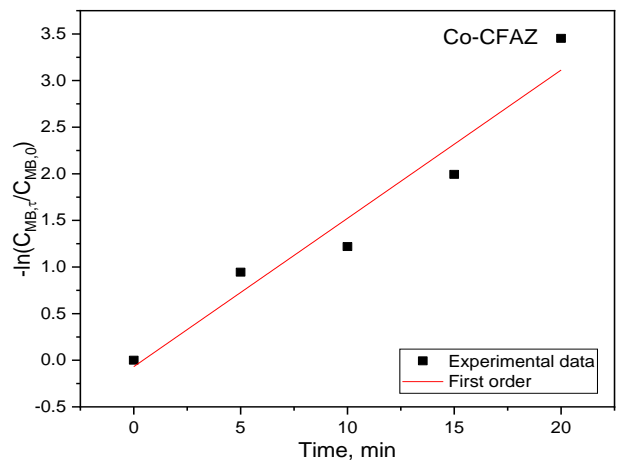

(c)

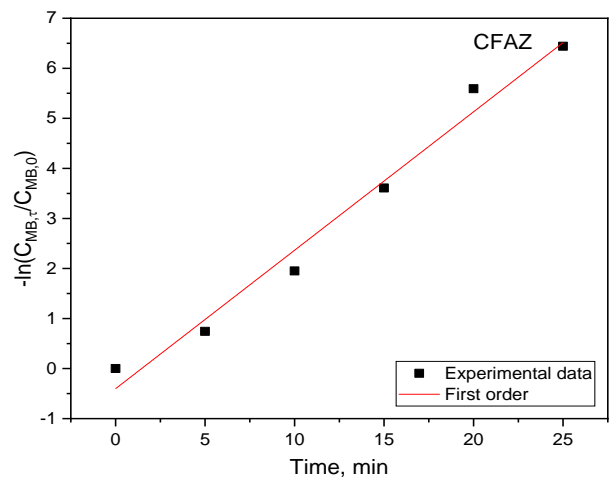

(e)

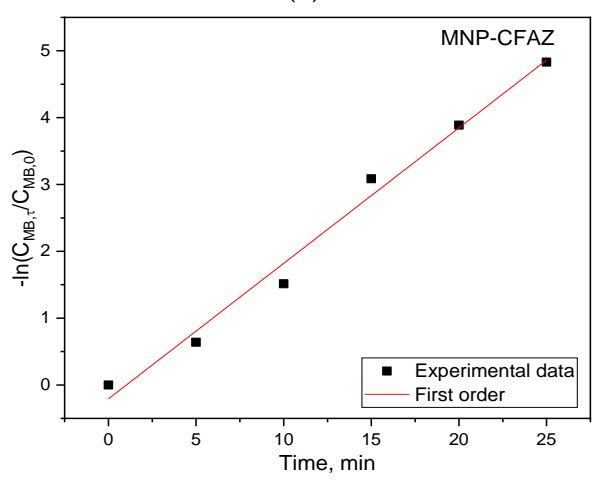

(g)

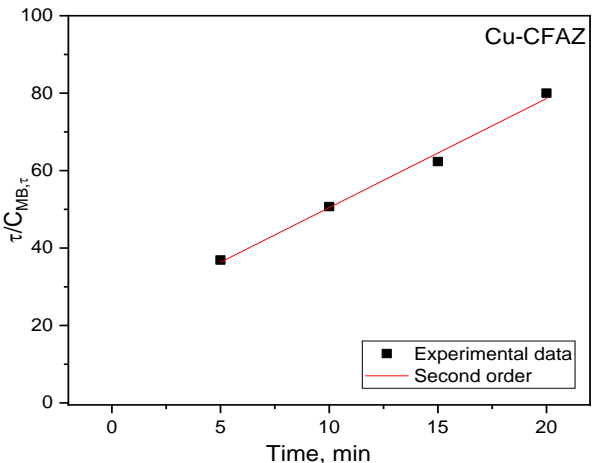

(b)

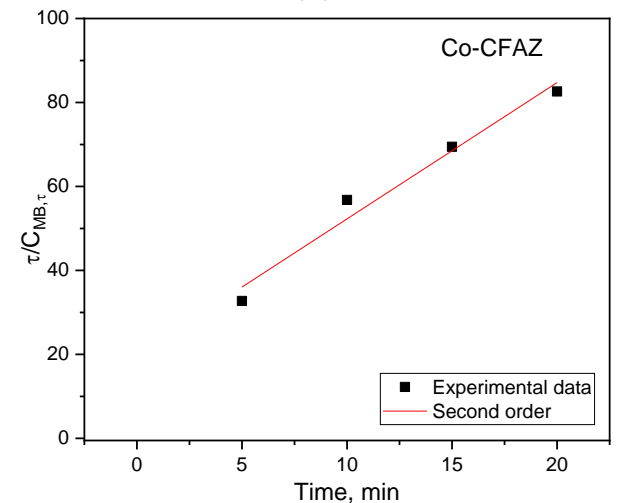

(d)

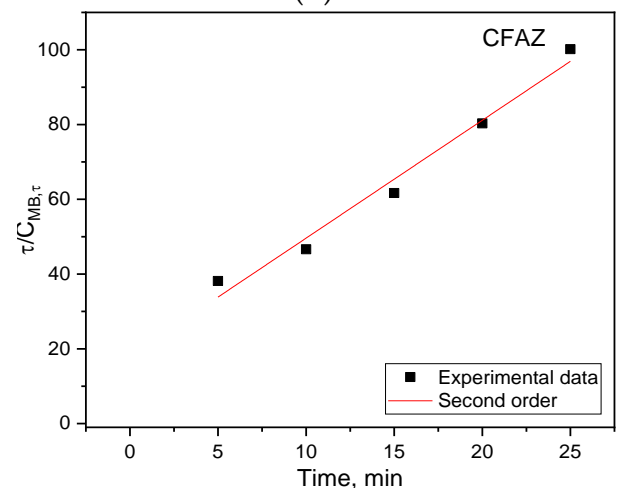

(f)

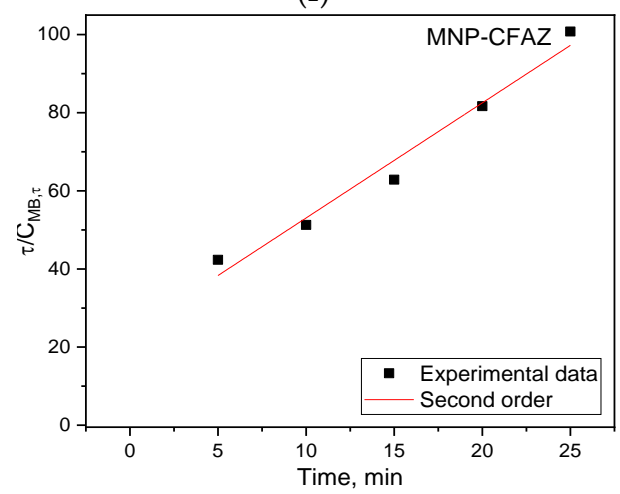

(h)

Figure 10. Pseudo first (PFO)- and second-order (PSO) reaction kinetics for degradation of MB by Fenton reaction onto CFAZ and modified CFAZ catalysts: (a) PFO of sample Cu-CFAZ; (b) PSO of sample Cu-CFAZ; (c) PFO of sample Co-CFAZ; (d) PSO of sample Co-CFAZ; (e) PFO of sample CFAZ; (f) PSO of sample CFAZ; (g) PFO of sample MNP-CFAZ; (h) PSO fo sample MNP-CFAZ. 


\section{Discussion}

Our previous studies revealed that due to the combination of ultrasonic-assisted homogenization and double-stage fusion-hydrothermal synthesis, the iron is distributed very finely into the zeolite matrix, mostly as $\mathrm{Fe}^{2+}$ - and $\mathrm{Fe}^{3+}$-cations [12]. It was found that the adsorption of $\mathrm{Cd}^{2+}$-ions from aqueous solutions on nonmodified and modified CFAZs obeys the Langmuir mechanism. This indicates that the monolayer adsorption mechanism is dominant in the investigated samples. Taking into account that the Langmuir model assumes a uniform distribution of the adsorption sites and surface energy, it could be supposed that the coal ash zeolites prepared by the combination of ultrasonic homogenization and two-step synthesis are characterized by a homogeneous distribution of iron oxide phases and other components transferred from the raw ash, despite the complex composition of the feedstock. In spite of the significantly higher value of the specific surface area of CFAZ, as compared to the one of MNP-CFAZ, the values obtained from model studies for monolayer adsorption capacity $\mathrm{Q}_{\text {sat }}$ are very similar for the two samples (Table 3). This indicates that although MNPs reduce the specific surface area of the zeolite, they most likely create a supplementary unsaturation of the surface, and therefore the adsorption properties are not deteriorated. Modification with copper and cobalt oxide particles significantly impairs both the surface properties of the specimens and their adsorption capacity with respect to $\mathrm{Cd}^{2+}$-ions. Comparative studies of the removal efficiency values of the CFAZs revealed a declination of $\mathrm{R}$-values towards $\mathrm{Cd}^{2+}$-ions at solution concentrations of $100 \mathrm{mg} / \mathrm{L}$, more pronounced at $\mathrm{Co}-\mathrm{CFAZ}$ and $\mathrm{Cu}-\mathrm{CFAZ}$. The retention capacity of all zeolite samples to $\mathrm{Pb}^{2+}$-ions remains high at these concentration levels.

It has been established that the main factor inhibiting the adsorption of metal ions from aqueous media onto porous adsorbents is the size of the metal-hydrated ion [40]. Values for hydrated ionic radii for $\mathrm{Pb}^{2+}$ and $\mathrm{Cd}^{2+}$ are reported as 4.01 and $4.26 \AA$, correspondingly [43]. The sorption affinity decreases with increasing the size of the metal-hydrated ion, which explains the higher removal efficiency of $\mathrm{Pb}^{2+}$-ions compared to $\mathrm{Cd}^{2+}$-ions by increasing the concentration of the treated aqueous solutions. Other studies also have shown greater retention of $\mathrm{Pb}^{2+}$-ions onto zeolites in competition with $\mathrm{Cd}^{2+}$-ions [40]. The removal efficiency of $\mathrm{Cd}^{2+}$-ions decreases with increasing the concentration of test solutions above $100 \mathrm{mgCd}^{2+} / 1$ and the decrease of $\mathrm{R}$ is greater for $\mathrm{Cu}-\mathrm{CFAZ}$ and Co-CFAZ compared to CFAZ and MNP-CFAZ. This is explained by the lower specific surface area of the samples modified with copper and cobalt oxides. Most likely, the reduction in the $S_{B E T}$ values of the zeolites modified by postsynthesis wet impregnation is due to the filling of their micro- and mesopores with metal oxide particles. This is confirmed by the measured lower values for their internal volume, determined by micro- $\left(\mathrm{V}_{\text {micro }}\right)$ and mesopores $\left(\mathrm{V}_{\text {meso }}\right)$ (Table 1$)$. The decrease in the adsorption capacity of the samples due to the reduction of their specific surface area shows that the retention mechanism of $\mathrm{Cd}^{2+}$-ions is mainly adsorption instead of ion exchange. The retention of other heavy metal ions, such as $\mathrm{Cu}^{2+}$-ions and $\mathrm{Zn}^{2+}$-ions from coal ash zeolites of $\mathrm{Na}-\mathrm{X}$ type, is assumed to take place by an ion-exchange mechanism [40].

Magnetic nanoparticles are widely studied for the treatment of heavy metal polluted wastewater due to the unique combination of electrical and magnetic properties, high adsorption capacity, and environmental compatibility [44]. The main disadvantage of MNPs is their tendency to agglomerate, which reduces the contact surface with the treated medium. The solution to this problem is MNP impregnation in zeolite matrices, thus creating composites with high adsorption potential, which have the property to magnetize and are harmless in water purification. The application of powdered adsorbents for water purification provides a larger solid/liquid contact surface, which increases with decreasing particle size. This results in greater adsorption capacity and decontamination efficiency. However, the smaller size of the solids makes it difficult to remove them from the treated medium at the end of the process. Magnetic zeolites have the advantage of technologically feasible solid/liquid separation from the treated media by applying an external magnet. The magnetic separation of adsorbents from water flows is very advantageous for industrial applications as it saves energy and time compared to alternative separation processes, such as filtration, centrifugation, or gravity separation. 
Maghemite nanoparticles $\left(\gamma-\mathrm{Fe}_{2} \mathrm{O}_{3}\right)$, and maghemite/silica nanocomposite $\left(\gamma-\mathrm{Fe}_{2} \mathrm{O}_{3} / \mathrm{SiO}_{2}\right)$, have been evaluated as magnetic heterogeneous Fenton catalysts [45]. It has also been found that the maghemite-loaded nanocomposites possess a strong magnetic susceptibility and can be easily recovered by magnetic settlement [45]. In the case of MNP modified zeolites, despite the significant reduction of the specific surface, their adsorption capacity is comparable to that of the parent sample. This is explained by the additional surface instauration of MNP-CFAZ, as the iron atoms in the maghemite have unpaired electrons in $3 \mathrm{~d}$ orbit and the presence of cation vacancies, which leads to additional electrostatic attraction [46]. Superparamagnetic characteristics of $\gamma-\mathrm{Fe}_{2} \mathrm{O}_{3}$ nanoparticles favor their less agglomeration; however, they reveal strong magnetic susceptibility when an external magnetic field is applied [46]. Magnetic zeolites have the technological advantage of being easily removed from the treated media by applying an external magnetic field. It has been found that the maghemite creates $\mathrm{Fe}-\mathrm{OH}$ and $\equiv \mathrm{Fe}-\mathrm{O}^{-}$active surface sites, which act as a Lewis base [47]. These active sites take place in the formation of complexes with heavy metal ions, thus retaining them on the surface of the adsorbent [47]. Moreover, heavy metal ions can also occupy vacancies in tetrahedral places, which further facilitate their adsorption.

When the degradation of MB by Fenton oxidation takes place at $90{ }^{\circ} \mathrm{C}$, all studied catalytic systems, consisting of zeolite support and active metal oxide centers, possess a high catalytic ability. Under these conditions, the parent CFAZ exhibits the highest catalytic activity due to the larger contact surface that the zeolite matrix provides. However, as the temperature decreases, the additional active catalytic centers created by modification of CFAZ contribute to the integral oxidation process. It has been observed that magnetite superior maghemite is a catalyst for advanced oxidation processes, as the $\mathrm{Fe}^{3+} / \mathrm{H}_{2} \mathrm{O}_{2}$ oxidation system is less active than the $\mathrm{Fe}^{2+} / \mathrm{H}_{2} \mathrm{O}_{2}$ because of the lower reactivity of $\mathrm{Fe}^{3+}$ with $\mathrm{H}_{2} \mathrm{O}_{2}$ [48]. However, a number of studies have shown that magnetite is oxidized to maghemite in Fenton oxidizing environments, and the residual Fe(II) content in the catalyst core, when nanoparticles are used, is of minor benefit for the catalytic activity [49]. Moreover, the catalytic activity and the stability of the $\gamma-\mathrm{Fe}_{2} \mathrm{O}_{3} / \mathrm{CFAZ}$ system can be improved by doping with copper oxide, which is to be further investigated. This is obeyed by the assumption that $\mathrm{Cu}^{2+}$-ions can replace $\mathrm{Fe}^{3+}$-ions in the crystal unit cell of maghemite due to its structural disorder. Co-CFAZ and Cu-CFAZ show higher catalytic activity than the parent sample, but MNP-CFAZ is ahead of them. This is due to the fact that the oxidation is carried out at low $\mathrm{pH}$ values in the acidic region, where maghemite is a better catalyst, while copper and cobalt oxides are more active at $\mathrm{pH}$ values close to neutral. The effect of $\mathrm{pH}$ on the catalytic behavior of nonmodified and modified CFAZs is to be studied in Fenton oxidation of various organic pollutants.

\section{Conclusions}

Coal fly ash zeolites with nanocrystalline morphology and with a mixed micro-mesoporous texture were synthesized from lignite coal fly ash by ultrasonic-assisted double-stage fusion-hydrothermal activation. The parent zeolites were loaded by maghemite nanoparticles and copper and cobalt oxides by in-situ modification or by the postsynthesis wet impregnation technique. The specific surface area of the starting zeolites reaches values of $486 \mathrm{~m}^{2} / \mathrm{gCFAZ}$, whereas, when modified with metal oxides, the surface parameter is greatly reduced. Non-modified and modified coal fly ash zeolites were studied regarding their capacity to retain $\mathrm{Cd}^{2+}$ - and $\mathrm{Pb}^{2+}$-ions from water solutions. It was observed that all of the coal fly ash derived zeolites almost completely adsorb $\mathrm{Pb}^{2+}$-ions from the treated water, up to concentrations of $100 \mathrm{mg} / \mathrm{L}$. All zeolites were found to be effective in cadmium ion removal up to concentration levels of $50 \mathrm{mg} / \mathrm{L}$. At higher concentrations of $\mathrm{Cd}^{2+}$-ions, stronger adsorption was observed by the parent and activated with maghemite nanoparticle zeolites, with adsorption capacity values exceeding $160 \mathrm{mgCd}^{2+} / \mathrm{gCFAZ}$. Model calculations show a mechanism of monolayer adsorption on all samples correlating with the Langmuir model. The highest adsorption capacities of zeolites were found at a $\mathrm{pH}$ range of 5-7 for cadmium ions and 3-5 for lead ions. The nonmodified and modified CFAZ reveal high catalytic activity in a Fenton oxidation process of methylene blue at $90^{\circ} \mathrm{C}$, but at 
lower temperatures, higher catalytic activity was established for the modified zeolites. The kinetics of the oxidation process is reliably described by the pseudo first-order kinetic equation at CFAZ and MNP-CFAZ and by the pseudo second-order kinetic equation at $\mathrm{Cu}-\mathrm{CFAZ}$ and $\mathrm{Co}-\mathrm{CFAZ}$. Studies have shown that parent and magnetic zeolites are effective for cadmium adsorption and all samples for lead adsorption, and metal oxide modified zeolites are preferable in the Fenton oxidation process.

Author Contributions: Conceptualization, S.B.; methodology, S.B., M.V., D.M.B., and M.P.; software, S.M., I.M., and D.Z.; validation, S.B., M.V., and D.Z.; formal analysis, D.Z. and D.M.B.; investigation, S.M., I.M., D.M.B., D.Z., and I.T.; resources, S.B.; data curation, D.Z.; writing-original draft preparation, S.B.; writing-review and editing, S.B., D.Z., and M.P.; visualization, D.Z. and S.B.; supervision, S.B. and M.V.; project administration, S.B. and M.V.; funding acquisition, S.B. and M.V. All authors have read and agreed to the published version of the manuscript.

Funding: This research was funded by National Science Fund, Ministry of Education, and Science of R. Bulgaria under the Grant DNTS Slovak Republic 01/6. The APC was funded by the Technical University of Sofia. The authors thank Károly Lázár from the Centre of Energy Research, Department of Nuclear Analysis, Hungarian Academy of Sciences, Budapest, for the Mössbauer spectroscopic measurements.

Conflicts of Interest: The authors declare no conflict of interest.

\section{References}

1. Gollakota, A.R.; Volli, V.; Shu, C.-M. Progressive utilisation prospects of coal fly ash: A review. Sci. Total Environ. 2019, 672, 951-989. [CrossRef]

2. Yao, Z.; Ji, X.; Sarker, P.; Tang, J.; Ge, L.; Xia, M.; Xi, Y. A comprehensive review on the applications of coal fly ash. Earth-Sci. Rev. 2015, 141, 105-121. [CrossRef]

3. Iyer, R.; Scott, J. Power station fly ash-A review of value-added utilization outside of the construction industry. Resour. Conserv. Recycl. 2001, 31, 217-228. [CrossRef]

4. Querol, X.; Moreno, N.; Umaña, J.; Alastuey, A.; Hernández, E.; Lopez-Soler, A.; Plana, F. Synthesis of zeolites from coal fly ash: An overview. Int. J. Coal Geol. 2002, 50, 413-423. [CrossRef]

5. Murayama, N.; Yamamoto, H.; Shibata, J. Mechanism of zeolite synthesis from coal fly ash by alkali hydrothermal reaction. Int. J. Miner. Process. 2002, 64, 1-17. [CrossRef]

6. Zgureva, D.; Boycheva, S. Synthesis of Highly Porous Micro- and Nanocrystalline Zeolites from Aluminosilicate By-Products. Count. Chem. Biol. Terror. East Eur. Ctries. 2014, 39, 199-204.

7. Franus, W.; Wdowin, M.; Franus, M. Synthesis and characterization of zeolites prepared from industrial fly ash. Environ. Monit. Assess. 2014, 186, 5721-5729. [CrossRef] [PubMed]

8. Belviso, C.; Cavalcante, F.; Fiore, S. Synthesis of zeolite from Italian coal fly ash: Differences in crystallization temperature using seawater instead of distilled water. Waste Manag. 2010, 30, 839-847. [CrossRef] [PubMed]

9. R., C.A.R.; Williams, C.; Roberts, C.L. A comparative study of two methods for the synthesis of fly ash-based sodium and potassium type zeolites. Fuel 2009, 88, 1403-1416. [CrossRef]

10. Boycheva, S.V.; Zgureva, D.M. Surface studies of fly ash zeolites via adsorption/desorption isotherms. Bulg. Chem. Commun. 2016, 48, 101-107.

11. Boycheva, S.; Marinov, I.; Miteva, S.; Zgureva, D. Conversion of coal fly ash into nanozeolite Na-X by applying ultrasound assisted hydrothermal and fusion-hydrothermal alkaline activation. Sustain. Chem. Pharm. 2020, 15, 100217. [CrossRef]

12. Sivalingam, S.; Sen, S. Rapid ultrasound assisted hydrothermal synthesis of highly pure nanozeolite $X$ from fly ash for efficient treatment of industrial effluent. Chemosphere 2018, 210, 816-823. [CrossRef] [PubMed]

13. Popova, M.; Boycheva, S.; Lazarova, H.; Zgureva, D.; Lázár, K.; Szegedi, Á. VOC oxidation and $\mathrm{CO}_{2}$ adsorption on dual adsorption/catalytic system based on fly ash zeolites. Catal. Today 2019. [CrossRef]

14. Supelano, G.; Cuaspud, J.G.; Moreno-Aldana, L.C.; Ortiz, C.; Trujillo, C.; Palacio, C.; Vargas, C.P.; Gómez, J.M. Synthesis of magnetic zeolites from recycled fly ash for adsorption of methylene blue. Fuel 2020, 263, 116800. [CrossRef]

15. Boycheva, S.; Zgureva, D.; Vassilev, V. Kinetic and thermodynamic studies on the thermal behaviour of fly ash from lignite coals. Fuel 2013, 108, 639-646. [CrossRef]

16. Feng, D.; Aldrich, C.; Tan, H. Removal of heavy metal ions by carrier magnetic separation of adsorptive particulates. Hydrometallurgy 2000, 56, 359-368. [CrossRef] 
17. Wang, S.; Peng, Y. Natural zeolites as effective adsorbents in water and wastewater treatment. Chem. Eng. J. 2010, 156, 11-24. [CrossRef]

18. Townsend, R.P.; Coker, E.N. Chapter 11 Ion exchange in zeolites. Adv. Pharmacol. 2001, 137, 467-524. [CrossRef]

19. Querol, X.; Moreno, N.; Umaña, J.C.; Juan, R.; Hernandez, S.; Fernandez-Pereira, C.; Ayora, C.; Janssen, M.; García-Martínez, J.; Linares-Solano, A.; et al. Application of zeolitic material synthesised from fly ash to the decontamination of waste water and flue gas. J. Chem. Technol. Biotechnol. 2002, 77, 292-298. [CrossRef]

20. Visa, M. Synthesis and characterization of new zeolite materials from fly ash for heavy metal removal in advanced water treatment. Powder Technol. 2016, 204, 338-347. [CrossRef]

21. He, X.; Yao, B.; Xia, Y.; Huang, H.; Gan, Y.; Zhang, W. Coal fly ash derived zeolite for highly efficient removal of $\mathrm{Ni}^{2+}$ inwaste water. Powder Technol. 2020, 367, 40-46. [CrossRef]

22. Joseph, I.; Tosheva, L.; Doyle, A. Simultaneous removal of $\mathrm{Cd}(\mathrm{II}), \mathrm{Co}(\mathrm{II}), \mathrm{Cu}(\mathrm{II}), \mathrm{Pb}(\mathrm{II})$, and $\mathrm{Zn}$ (II) ions from aqueous solutions via adsorption on FAU-type zeolites prepared from coal fly ash. J. Environ. Chem. Eng. 2020, 8, 103895. [CrossRef]

23. Koshy, N.; Singh, D. Fly ash zeolites for water treatment applications. J. Environ. Chem. Eng. 2016, 4, 1460-1472. [CrossRef]

24. Wang, C.; Li, J.; Wang, L.; Sun, X.; Huang, J. Adsorption of Dye from Wastewater by Zeolites Synthesized from Fly Ash: Kinetic and Equilibrium Studies. Chin. J. Chem. Eng. 2009, 17, 513-521. [CrossRef]

25. Cunico, P.; Kumar, A.; Fungaro, D. Adsorption of dyes from simulated textile wastewater onto modified nanozeolite from coal fly ash. J. Nanosci. Nanoeng. 2015, 1, 148-161.

26. Olmos, R.G.; Roland, U.; Toufar, H.; Kopinke, F.-D.; Georgi, A. Fe-zeolites as catalysts for chemical oxidation of MTBE in water with H2O2. Appl. Catal. B 2009, 89, 356-364. [CrossRef]

27. Arimi, M.M. Modified natural zeolite as heterogeneous Fenton catalyst in treatment of recalcitrants in industrial effluent. Prog. Nat. Sci. 2017, 27, 275-282. [CrossRef]

28. Olmos, R.G.; Martín, M.J.; Georgi, A.; Kopinke, F.-D.; Oller, I.; Malato, S. Fe-zeolites as heterogeneous catalysts in solar Fenton-like reactions at neutral pH. Appl. Catal. B 2012, 125, 51-58. [CrossRef]

29. Singh, L.; Rekha, P.; Chand, S. Cu-impregnated zeolite $Y$ as highly active and stable heterogeneous Fenton-like catalyst for degradation of Congo red dye. Sep. Purif. Technol. 2016, 170, 321-336. [CrossRef]

30. Wang, N.; Xu, H.; Li, S. A microwave-activated coal fly ash catalyst for the oxidative elimination of organic pollutants in a Fenton-like process. RSC Adv. 2019, 9, 7747-7756. [CrossRef]

31. Ramírez, H.; Núñez, M.M.G.; Bogoya, A.B.; Gomez, D.F.B.; Ramos, C.; Di Luca, C.; Inchaurrondo, N.; Haure, P. Synthesis of coal fly ash zeolite for the catalytic wet peroxide oxidation of Orange II. Environ. Sci. Pollut. Res. 2018, 26, 4277-4287. [CrossRef]

32. Subbulekshmi, N.; Subramanian, E. Nano CuO immobilized fly ash zeolite Fenton-like catalyst for oxidative degradation of $\mathrm{p}$-nitrophenol and $\mathrm{p}$-nitroaniline. J. Environ. Chem. Eng. 2017, 5, 1360-1371. [CrossRef]

33. Boycheva, S.; Marinov, I.; Lazarova, H.; Zgureva, D.; Václavíková, M.; Popova, M. Cobalt- and copper-modified fly ash nanozeolites for environmental protection systems. In Proceedings of the CEST 2019, Rhodes, Greece, 4-7 September 2019; p. 563.

34. Simate, G.S.; Maledi, N.; Ochieng, A.; Ndlovu, S.; Zhang, J.; Walubita, L.F. Coal-based adsorbents for water and wastewater treatment. J. Environ. Chem. Eng. 2016, 4, 2291-2312. [CrossRef]

35. Sivalingam, S.; Kella, T.; Maharana, M.; Sen, S. Efficient sono-sorptive elimination of methylene blue by fly ash-derived nano-zeolite X: Process optimization, isotherm and kinetic studies. J. Clean. Prod. 2019, 208, 1241-1254. [CrossRef]

36. Tauanov, Z.; Tsakiridis, P.; Mikhalovsky, S.; Inglezakis, V.J. Synthetic coal fly ash-derived zeolites doped with silver nanoparticles for mercury (II) removal from water. J. Environ. Manag. 2018, 224, 164-171. [CrossRef] [PubMed]

37. Feng, W.; Wan, Z.; Daniels, J.; Li, Z.; Xiao, G.; Yu, J.; Xu, D.; Guo, H.; Zhang, D.; May, E.F.; et al. Synthesis of high quality zeolites from coal fly ash: Mobility of hazardous elements and environmental applications. J. Clean. Prod. 2018, 202, 390-400. [CrossRef]

38. Rebodos, R.L.; Vikesland, P.J. Effects of Oxidation on the Magnetization of Nanoparticulate Magnetite. Langmuir 2010, 26, 16745-16753. [CrossRef] 
39. Kim, W.; Suh, C.-Y.; Cho, S.-W.; Roh, K.-M.; Kwon, H.; Song, K.; Shon, I.-J. A new method for the identification and quantification of magnetite-maghemite mixture using conventional X-ray diffraction technique. Talanta 2012, 94, 348-352. [CrossRef]

40. Wang, C.; Li, J.; Sun, X.; Wang, L.; Sun, X. Evaluation of zeolites synthesized from fly ash as potential adsorbents for wastewater containing heavy metals. J. Environ. Sci. 2009, 21, 127-136. [CrossRef]

41. Belova, T. Adsorption of heavy metal ions $\left(\mathrm{Cu}^{2+}, \mathrm{Ni}^{2+}, \mathrm{Co}^{2+}\right.$ and $\left.\mathrm{Fe}^{2+}\right)$ from aqueous solutions by natural zeolite. Heliyon 2019, 5, e02320. [CrossRef]

42. Boparai, H.K.; Joseph, M.; O'Carroll, D.M. Kinetics and thermodynamics of cadmium ion removal by adsorption onto nano zerovalent iron particles. J. Hazard. Mater. 2011, 186, 458-465. [CrossRef] [PubMed]

43. Chen, S.B.; Ma, Y.; Chen, L.; Xian, K. Adsorption of aqueous $\mathrm{Cd}^{2+}, \mathrm{Pb}^{2+}, \mathrm{Cu}^{2+}$ ions by nano-hydroxyapatite: Single- and multi-metal competitive adsorption study. Geochem. J. 2010, 44, 233-239. [CrossRef]

44. El-Dib, F.I.; Mohamed, D.E.; El-Shamy, O.A.A.; Mishrif, M.R. Study the adsorption properties of magnetite nanoparticles in the presence of different synthesized surfactants for heavy metal ions removal. Egypt. J. Pet. 2020, 29, 1-7. [CrossRef]

45. Ferroudj, N.; Nzimoto, J.; Davidson, A.; Talbot, D.; Briot, E.; Dupuis, V.; Bée, A.; Medjram, M.S.; Abramson, S. Maghemite nanoparticles and maghemite/silica nanocomposite microspheres as magnetic Fenton catalysts for the removal of water pollutants. Appl. Catal. B 2013, 136, 9-18. [CrossRef]

46. Fopase, R.; Pandey, L.M. Iron oxide magnetic nanomaterials for biomedical applications. In Magnetochemisty Materials and Applications; Boddula, I.R., Asiri, A.M., Eds.; Materials Research Forum LLC.: Millesville, PA, USA, 2020; Volume 66, pp. 276-322.

47. Guivar, J.A.R.; Sadrollahi, E.; Menzel, D.; Fernandes, E.G.R.; López, E.O.; Torres, M.M.; Arsuaga, J.M.; Arencibia, A.; Litterst, F.J. Magnetic, structural and surface properties of functionalized maghemite nanoparticles for copper and lead adsorption. RSC Adv. 2017, 7, 28763-28779. [CrossRef]

48. Pignatello, J.J. Dark and photoassisted $\mathrm{Fe}^{3+}$-catalysed degradation of chlorophenoxy herbicides by hydrogen peroxide. Environ. Sci. Technol. 1992, 26, 944. [CrossRef]

49. Rusevova, K.; Kopinke, F.-D.; Georgi, A. Nano-sized magnetic iron oxides as catalysts for heterogeneous Fenton-like reactions-Influence of Fe(II)/Fe(III) ratio on catalytic performance. J. Hazard. Mater. 2012, 241, 433-440. [CrossRef] 